Article

\title{
Development of a Meteorological Risk Map for Disaster Mitigation and Management in the Chishan Basin, Taiwan
}

\author{
Tai-Li Lee ${ }^{1}$, Ching-Ho Chen ${ }^{2}$, Tzu-Yi Pai ${ }^{3}$ and Ray-Shyan Wu ${ }^{1, *}$ \\ 1 Department of Civil Engineering, National Central University, Chung-Li 32054, Taiwan; \\ E-Mail: alibi0611@gmail.com
}

2 Department of Social and Regional Development, National Taipei University of Education, Taipei 10671, Taiwan; E-Mail: chchen@tea.ntue.edu.tw

3 Department of Science Application and Dissemination, National Taichung University of Education, Taichung 40306, Taiwan; E-Mail: bai@ms6.hinet.net

* Author to whom correspondence should be addressed; E-Mail: raywu@ncu.edu.tw; Tel.: +886-3-4227151 (ext. 34126); Fax: +886-3-4252960.

Academic Editor: Yu-Pin Lin

Received: 3 October 2014 / Accepted: 8 January 2015 / Published: 16 January 2015

\begin{abstract}
This study involved developing a natural disaster risk assessment framework based on the consideration of three phases: a pre-disaster phase, disaster impact phase, and post-disaster recovery phase. The exposure of natural disasters exhibits unique characteristics. The interactions of numerous factors should be considered in risk assessment as well as in monitoring environment to provide natural disaster warnings. In each phase, specific factors indicate the relative status in the area subjected to risk assessment. Three types of natural disaster were assessed, namely debris flows, floods, and droughts. The Chishan basin in Taiwan was used as a case study and the adequacy of the relocation of Xiaolin village was evaluated. Incorporating resilience into the assessment revealed that the higher the exposure is, the higher the resilience becomes. This is because highly populated areas are typically allocated enough resources to respond to disasters. In addition, highly populated areas typically exhibit high resilience. The application of this analysis in the policy of relocation of damaged village after disaster provides valuable information for decision makers to achieve the sustainability of land use planning.
\end{abstract}

Keywords: risk assessment; resilience; risk maps 


\section{Introduction}

Accurately predicting natural disasters is highly challenging. Worldwide disaster prevention and response mechanisms employ warning and risk-assessment systems to provide decision makers and the public with information about the dangers of living in areas affected by natural disasters. However, regarding river basins, the interrelationships among human society, the water environment, the land environment, and climate as well as long-term tendencies have not been systematically researched. This study involved developing an effective assessment framework for natural disaster risk assessment. Based on the concepts of warning and risk assessment proposed by the United Nations Inter-Agency Secretariat of the International Strategy for Disaster Reduction [1], methods and technologies for risk assessment and systems analysis were employed to identify the relationships among the factors causing natural disasters, and these relationships were presented in a geographic information system (GIS). This study proposes a model that enables calculating the risk of natural disasters in each specific location in the study area, namely Chishan basin in Southern Taiwan. The hazard indicators reflect the probability of occurrence and severity of disasters [2]. The loss indicators indicate the loss of life, economy, and employment as well as habitation environments. The concept of resilience is incorporated in the construction of risk map [3,4]. In general, resilience can refer to any one or more of the following: socio-cultural, economic, community disaster remediation capacity, institutional and infrastructure $[5,6]$. Let it be noted that relicenses in this study specifically refers to infrastructure resilience, namely debris relief facilities, water supply systems and flood remediation facilities. Other measures, such as spatial variation in the distribution of especially vulnerable populations (e.g., the elderly) and locations of informal settlements (e.g., shanties and favelas), are not considered for the lack of information.

In dealing with natural disaster reduction management, this study addressed three aspects, namely Hazard, Exposure, and Resilience. Three categories of natural disaster were assessed, namely debris flows, floods, and droughts. Each type of natural disaster has distinct assessment factors. Among the three aspects of natural disasters, the exposure to natural disasters exhibited distinct characteristics. In addition, the interactions of these aspects were considered in risk assessment and in monitoring conducted to provide natural disaster warnings. The Chishan basin was examined in a case study, and the advantage of relocating Xiaolin village was discussed. The analysis is shown in a GIS containing grids with a 336 resolution of $200 \mathrm{~m} \times 200 \mathrm{~m}$. With the incorporation of resilience into the assessment revealed that exposure and the resilience are both high in the same location. This is because highly populated areas usually have adequate resources to respond. The analysis on resilience provides useful information in the allocation of resources to respond to the disaster. Based on the findings, redeveloping Xiaolin village on the original site of the village is proposed as an alternative way other than relocation in this specific case study.

\section{Model Formulation}

The disaster risk assessment framework developed in this study comprises three elements: the hazard, the degree of exposure to hazards (exposure), and the degree of disaster recovery (resilience). Therefore, risk was defined as a function of the following three elements, as Equation (1). 


$$
\text { Risk }=\mathrm{f}(\mathrm{H}, \mathrm{E}, \mathrm{R})
$$

where Risk is the value of disaster risk, and H, E, and R represent the hazard danger, degree of exposure to hazards, and ability to recover from disaster of the affected objects, respectively. The disaster risk values are affected by all three elements. Furthermore, when a single element is lacking, even though the other elements have a substantial value, the risk is not severe. Therefore, the relationships among the three elements are mainly expressed in the form of multiplication. The risk equation, which is similar to the United Nations' 2002 risk calculation equation, is expressed as follows (Equation (2)):

$$
\text { Risk }=\mathrm{H} \times \mathrm{E} \times(1-\mathrm{R})
$$

The original United Nations' 2002 risk calculation involved determining risk by hazard multiplying exposure, and then divided by resilience. However, areas with low levels of development often exhibit a low ability to recover from disasters, and in some cases, no resilience. Consequently, the UN model tends to overestimate the risk in underdeveloped areas. Therefore, in this study, risk was calculated by multiplying unity minus resilience. The higher the resilience is, the more a risk can be reduced. In addition, for areas with low resilience, risk can be calculated because resilience exerts no influence in these areas. In other words, resilience does not lower risk.

The risk value obtained using normalized risk assessment should be between 0 and 1 to enable the risk to be classified into levels easily. Because all three elements are multiplied in Equation (2), the risk can be as low as 0.125 when all elements are 0.5 . Therefore, the cube root of risk in Equation (2) was calculated in this study to denote a risk assessment value [7]. In this case, the risk was between 0 and 1, as shown in Equation (3):

$$
\text { Risk }=\sqrt[3]{\mathrm{H} \times \mathrm{E} \times(1-\mathrm{R})}
$$

Risk levels are divided into five intervals by using $0.2,0.4,0.6$, and 0.8 as cutoff values. The five intervals denoted very low risk, low risk, medium risk, high risk, and very high risk. This classification system is chosen to present the relative risk in the GIS Map. The following section introduces the formulation of all indices for the risk assessments. The indices or factors are normalized to be dimensionless values between 0 and 1 .

\subsection{Debris Flow Risk Assessment}

The risk of debris flow is analyzed according to the pre-disaster phase, disaster impact phase, and post-disaster recovery phase. Each phase is represented by a specific indicator to assess the related disaster phase, namely, debris flow hazard, debris flow exposure, and debris flow resilience [8-11].

\subsubsection{Debris Flow Hazard}

The probability of debris flow occurrence, the intensity of debris flow, and the range of debris flow are the three factors used for assessing debris flow hazard in the proposed framework. When the probability of debris flow occurrence is 0 , even when both the intensity and the scope of debris flow are high, no hazard to the built environment is present. A similar concept can be applied to the 
intensity and scope of debris flow. Therefore, the following equation was proposed to define debris flow hazard:

$$
\mathrm{H}_{\mathrm{d}}=\sqrt[3]{\mathrm{H}_{\mathrm{d}} \mathrm{P} \times \mathrm{H}_{\mathrm{d}} \mathrm{I} \times \mathrm{H}_{\mathrm{d}} \mathrm{R}}
$$

where $\mathrm{H}_{d}$ is the debris flow hazard indicator, $\mathrm{H}_{\mathrm{d}} \mathrm{P}$ is the probability of debris flow occurrence, $\mathrm{H}_{\mathrm{d}} \mathrm{I}$ is the intensity of debris flow, and $\mathrm{H}_{\mathrm{d}} \mathrm{R}$ is the range of debris flow. The three factors in Equation (4) were estimated based on various findings in the literature and described in detail by $\mathrm{Li}$ in [12]. The probability of debris flow occurrence is based on three factors observed in the field, namely, the moisture condition, slope condition, and supplying material. The moisture condition is represented by the catchment shape coefficient and rainfall alert threshold. The slope condition is represented by the average catchment slope and effective catchment area. The supplying material is represented by the landslide ratio and geological zonation. In Taiwan, a specific rainfall alert threshold is assigned to each watershed. This value is used to normalize the relative tendency in decries flow under heavy rainfall.

The intensity of debris flow was estimated based on the relative mass of debris flow from each subwatershed compared with the maximal mass of debris flow from a subwatershed in the investigated watershed. The scope of debris flow was estimated based on information on the potential debris flow location and spreading area estimated by the Taiwan Soil and Water Conservation Bureau.

\subsubsection{Debris Flow Exposure}

The exposure of the affected area is based on three factors, namely the number of residential units, population density, and the distance from the point where the disaster occurred. Because the degree of exposure is assessed based on the severity of the effect on people's safety caused by debris flow, the number of residential units and people living in the affected area were used to estimate exposure [13]. Another crucial factor is the distance from the point where the disaster occurred, which is used as the weighting factor. The exposure can be defined as Equation (5):

$$
E_{d}=\sqrt{\left(\frac{E_{d} W}{2}+\frac{E_{d} H}{2}\right) \times E_{d} L}
$$

where $E_{d}$ is the exposure of debris flow, $E_{d} W$ is the number of residential units, $E_{d} H$ is the population density, and $E_{d} L$ is the distance from the point where the disaster occurred. All of these factors are normalized to be dimensionless values between 0 and 1 . Let it be noted that only the factors involved in the equations are normalized, the products are presented as the exact values from the equations. The same approaches are taken throughout this study.

\subsubsection{Debris Flow Resilience}

Resilience is defined as the ability to recover from a disaster [14-17]. Let the available resources of relief be estimated based on (a) the effectiveness of rescue facilities; and (b) the location of the rescue facilities, resilience then can be assessed by the available resources of relief and the roads available to mobilize required equipment. Resilience can be expressed as Equation (6):

$$
\mathrm{R}_{\mathrm{d}}=\sqrt{\mathrm{R}_{\mathrm{d}} \mathrm{H} \times \mathrm{R}_{\mathrm{d}} \mathrm{P}}
$$


where $R_{d}$ is the resilience to debris flow, $R_{d} H$ is the availability of relief resources, and $R_{d} P$ is the distance from roads. The available resources considered for debris flow are the machineries for rescue and for the traffic maintaining. All factors are normalized to be between 0 and 1 .

\subsection{Flood Risk Assessment}

The risk of flood hazards is analyzed according to the pre-disaster phase, disaster impact phase, and post-disaster recovery phase. Each phase is represented by a specific indicator to assess the related disaster phase, namely, flood hazard, flood exposure, and flood resilience [18,19].

\subsubsection{Flood Hazard}

Flood hazard is the likelihood of a flood disaster. Flood disaster probability and the severity of flooding are employed as assessment indices. Flood hazard can be defined as follows:

$$
\mathrm{H}_{\mathrm{f}}=\sqrt{\mathrm{H}_{\mathrm{f}} \mathrm{h} \times \mathrm{H}_{\mathrm{f}} \mathrm{I}}
$$

where $\mathrm{H}_{\mathrm{f}}$ is the flood hazard, $\mathrm{H}_{\mathrm{f}} \mathrm{P}$ is the probability of flooding, and $\mathrm{H}_{\mathrm{f}} \mathrm{I}$ is the severity of flooding.

Physiographic factors, namely the catchment shape coefficient, elevation, natural slope, land use, and rainfall alert value, are used to assess the probability of flooding. The catchment shape coefficient, land use, and rainfall alert are indicators of the likelihood of flooding. None of these three factors are crucial. However, the elevation and natural slope are crucial factors in the occurrence of flooding for a given location. Both of the two indispensable factors are included in the equation in the form of multiplication. The equation for defining flood hazard is expressed as Equation (8):

$$
\mathrm{H}_{\mathrm{f}} \mathrm{P}=\sqrt[3]{\left(\frac{\mathrm{H}_{\mathrm{f}} \mathrm{m}_{1}}{3}+\frac{\mathrm{H}_{\mathrm{f}} \mathrm{m}_{2}}{3}+\frac{\mathrm{H}_{\mathrm{f}} \mathrm{m}_{3}}{3}\right) \times \mathrm{H}_{\mathrm{f}} \mathrm{Z} \times \mathrm{H}_{\mathrm{f}} \mathrm{S}}
$$

where $\mathrm{H}_{\mathrm{f}} \mathrm{P}$ is the probability of flooding, $\mathrm{H}_{\mathrm{f}} \mathrm{m}_{1}$ is the catchment shape coefficient, $\mathrm{H}_{\mathrm{f}} \mathrm{m}_{2}$ is the land use factor, $\mathrm{H}_{\mathrm{f}} \mathrm{m}_{3}$ is the rainfall alert value, $\mathrm{H}_{\mathrm{f}} \mathrm{Z}$ is the elevation of the area, and $\mathrm{H}_{\mathrm{f}} \mathrm{s}$ is the average slope in the region. Each factor value is set between 0 and 1 after normalization.

The severity of flooding can be estimated based on the depth and duration of flooding and expressed as Equation (9):

$$
\mathrm{H}_{\mathrm{f}} \mathrm{I}=\sqrt{\mathrm{H}_{\mathrm{f}} \mathrm{h} \times \mathrm{H}_{\mathrm{f}} \mathrm{t}}
$$

where $\mathrm{H}_{\mathrm{f}} \mathrm{I}$ is the severity of flooding, $\mathrm{H}_{\mathrm{f}} \mathrm{h}$ is the depth of the flood, $\mathrm{H}_{\mathrm{f}} \mathrm{t}$ is the duration of water logging. Again, all factors are normalized to be between 0 and 1 .

\subsubsection{Flood Exposure}

Flood exposure is estimated based on two factors, one is the estimation of economic loss and the other is the distance from a river. Here, the distance from to a river indicates the level of exposure, e.g., the further away from the river indicates the less the exposure is expected. Flood exposure can be expressed as Equation (10):

$$
E_{f}=\sqrt{E_{f} e \times E_{f} I}
$$


where $E_{\mathrm{f}}$ is flood exposure, $\mathrm{E}_{\mathrm{f}} \mathrm{e}$ is the economic loss exposure, and $\mathrm{E}_{\mathrm{f}} \mathrm{l}$ is the distance to a river. When $\mathrm{E}_{\mathrm{f}} \mathrm{e}$ is 0 , no economic loss occurs in the target area when flooding occurs. Therefore, even when the distance is short, the overall exposure is 0 .

\subsubsection{Flood Resilience}

Flood resilience is estimated based on typical measures applied in flood mitigation, namely the regional pumping stations, floodgate facilities, and the size of detention ponds. Flood damage and losses differ from those of debris flow and might not be irrecoverable [20,21]. Therefore, flood resilience should be estimated by investigating drainage conditions [22]. The drainage condition means the ability to drain water away from the flooding area. With good drainage condition, the time and depth of flood is minimized and no significant losses is realized. Pumping stations play a crucial role in preventing ponding in urban areas where floodwater cannot be discharged through based on gravity. Floodgate facilities and flood detention ponds can be used to partition, reallocate, or store excess runoff temporarily and, thus, mitigate the effects of flooding. The aforementioned three measures can be applied independently or jointly to mitigate flooding. Therefore, flood resilience can be expressed as Equation (11):

$$
\mathrm{R}_{\mathrm{f}}=\frac{\mathrm{R}_{\mathrm{f}} \mathrm{p}}{3}+\frac{\mathrm{R}_{\mathrm{f}} \mathrm{g}}{3}+\frac{\mathrm{R}_{\mathrm{f}} \mathrm{b}}{3}
$$

where $R_{f}$ is flood resilience, $R_{f} p$ is the factor associated with pumping stations, $R_{f} g$ is the factor associated with floodgate facilities, and $\mathrm{R}_{\mathrm{f}} \mathrm{b}$ is the factor associated with the size of detention ponds.

\subsection{Drought Risk Assessment}

The risk of drought is analyzed according to the pre-disaster phase, disaster impact phase, and post-disaster recovery phase. Each phase is represented by a specific indicator to assess the related disaster phase, namely, drought hazard, drought exposure, and drought resilience $[23,24]$.

\subsubsection{Drought Hazard}

Drought hazard is the degree of risk of drought. Drought risk at the first stage is assessed based on the probability of occurrence and severity of drought. Drought hazard can be expressed as shown in Equation (12):

$$
\mathrm{H}_{\mathrm{y}}=\sqrt{\mathrm{H}_{\mathrm{y}} \mathrm{P} \times \mathrm{H}_{y} \mathrm{I}}
$$

where $\mathrm{H}_{\mathrm{y}}$ is the drought hazard, $\mathrm{H}_{\mathrm{y}} \mathrm{P}$ is the probability of drought, and $\mathrm{H}_{\mathrm{y}} \mathrm{I}$ is the severity of drought.

The probability of drought is mainly based on climatic conditions (i.e., a longer period of rain-free time results in a higher probability of drought). The recorded maximal number of consecutive rain-free (daily rainfall $<0.6 \mathrm{~mm}$ ) days in the analysis case is employed as a normalized criterion to assess the probability of drought. Then the probability of drought is represented as the maximum number of consecutive rain-free days for the specific location divided by the recorded maximum number of consecutive rain-free days for the whole region. On the other hand, the severity of drought is expressed 
as the water demand for the specific location divided by the maximum water demand in the whole region. A greater demand for water leads to a higher severity of drought.

\subsubsection{Drought Exposure}

The second part of the drought risk assessment involved estimating the possible damage caused by drought. Three types of water usage were identified, namely agricultural, domestic, and industrial. In agriculture, water shortages cause unproductive harvests; thus, crop production can be used as an indicator of exposure. Regarding domestic use, the supply of water required to meet a population's total water demand is used as an indicator of exposure. Regarding industry, the insufficient supply of water is employed as an indicator for exposure. Drought exposure is assessed using Equation (13):

$$
\mathrm{E}_{y}=\frac{\mathrm{E}_{\mathrm{y}} \mathrm{a}}{3}+\frac{\mathrm{E}_{\mathrm{y}} \mathrm{c}}{3}+\frac{\mathrm{E}_{\mathrm{y}} \mathrm{i}}{3}
$$

where $\mathrm{E}_{y}$ is the drought exposure rate, $\mathrm{E}_{\mathrm{y}} \mathrm{a}$ is the agricultural water exposure indicator, $\mathrm{E}_{\mathrm{y}} \mathrm{c}$ is the domestic water exposure indicator, and $\mathrm{E}_{\mathrm{y}} \mathrm{i}$ is the industrial water exposure indicator. All factors are normalized to be between 0 and 1 .

\subsubsection{Drought Resilience}

Drought resilience depends on the capacity to adjust water allocation within a region, which can be analyzed based on regional water storage facilities and water treatment plants [25]. Water supply systems can be analyzed to determine the capability to reduce risk. The higher the resilience is, the more the risk is reduced [26-28]. Drought resilience can be evaluated based on two factors: the distances to waterworks and the storage capacities of reservoirs. The greater the distance to waterworks is, the more difficult it is to supply water. In addition, a larger storage facility has a greater capacity to minimize the adverse effects of drought. Therefore, drought resilience can be expressed as Equation (14):

$$
\mathrm{R}_{\mathrm{y}}=\frac{\mathrm{R}_{\mathrm{y}} \mathrm{w}}{2}+\frac{\mathrm{R}_{\mathrm{y}} \mathrm{r}}{2}
$$

where $R_{y}$ is the drought resilience, $R_{y} w$ is the indicator related to the distance to waterworks, and $\mathrm{R}_{\mathrm{y}} \mathrm{r}$ is the indicator related to the storage capacities of the reservoirs. All factors are normalized to be between 0 and 1 .

\section{Results and Discussion}

The Chishan basin, located in Southern Taiwan, was the subject of a case study. The proposed models were employed to calculate the risk of natural disasters at each location in the designated area. Each location was represented by a square in a grid with a resolution of $200 \mathrm{~m} \times 200 \mathrm{~m}$. The river basin was investigated to produce hazard maps for use in land management. 


\subsection{Debris Flow Risk Analysis}

Figures 1-5 depict the debris flow risk maps of the study area. The debris flow risk in the downstream area was higher than that in the upstream area. This is because the exposure was higher in the downstream area and the debris-affected area was mainly located downstream.

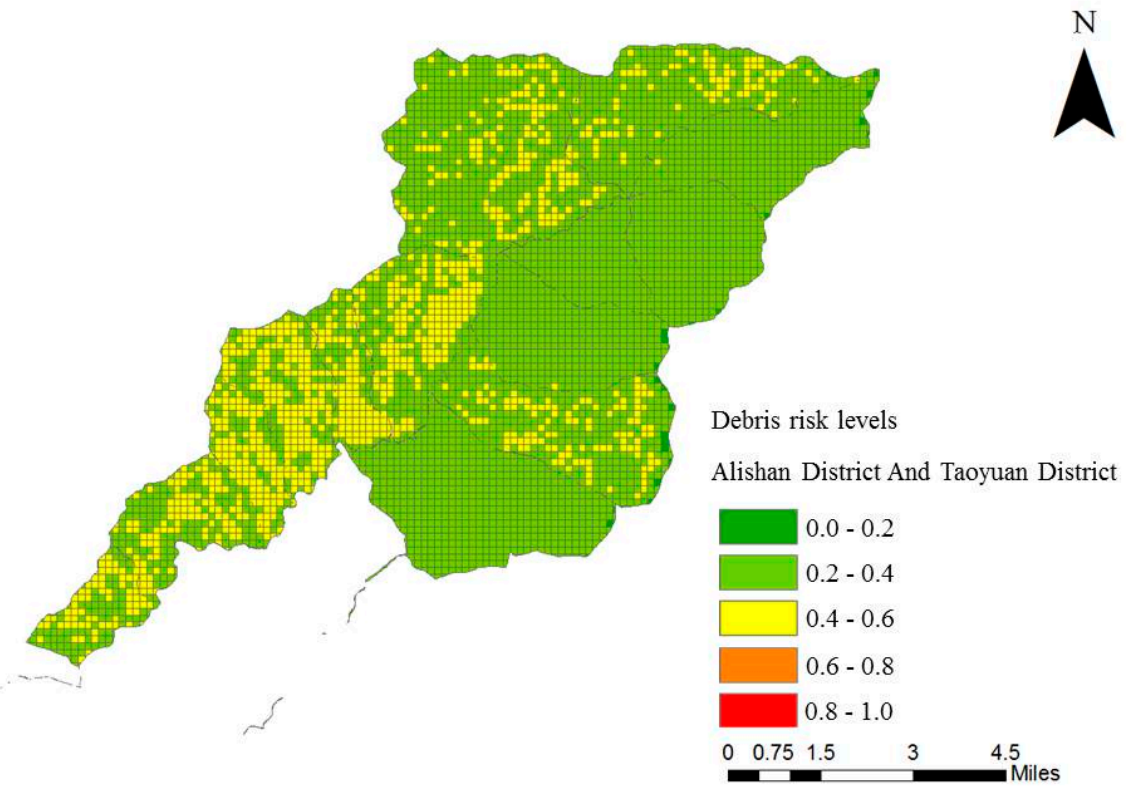

Figure 1. Debris risk map of Alishan District and Taoyuan District.
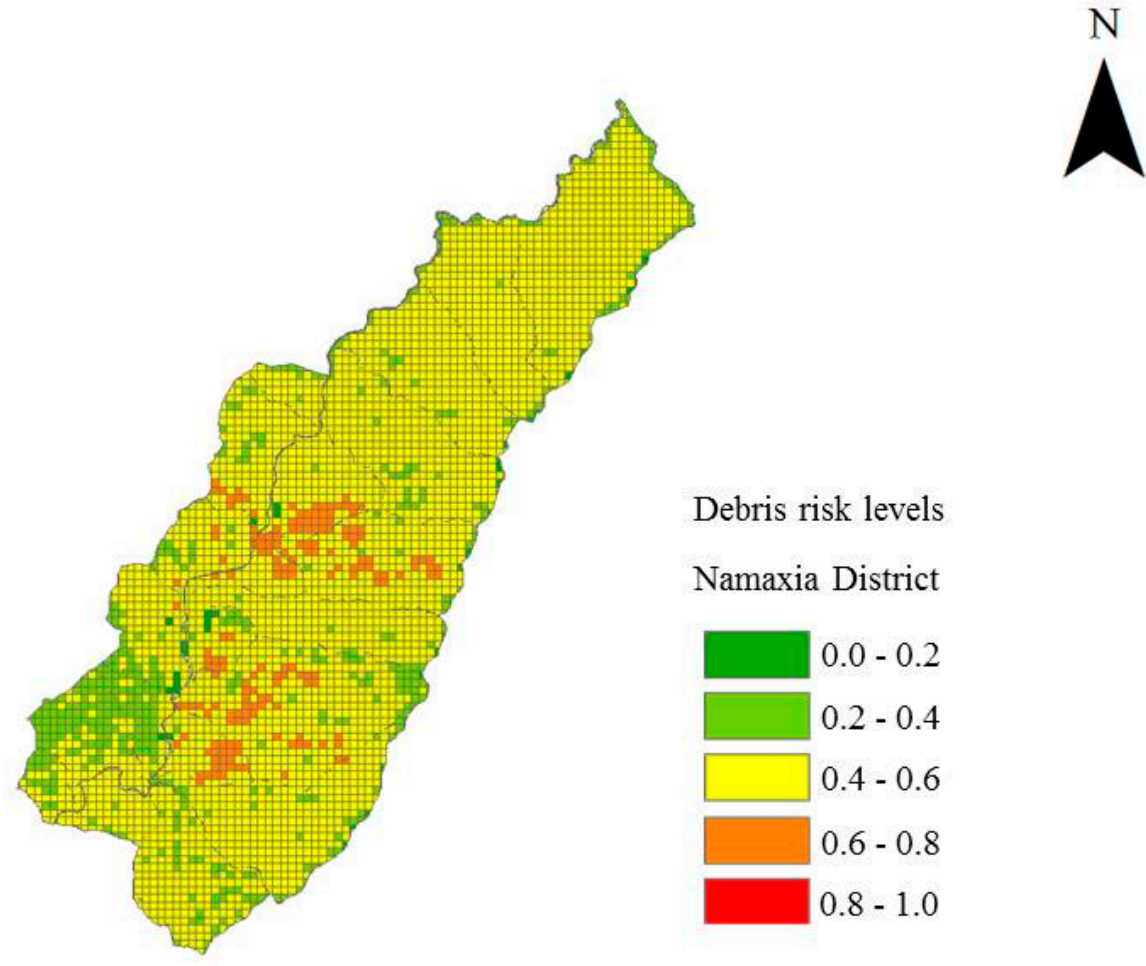

Debris risk levels

Namaxia District
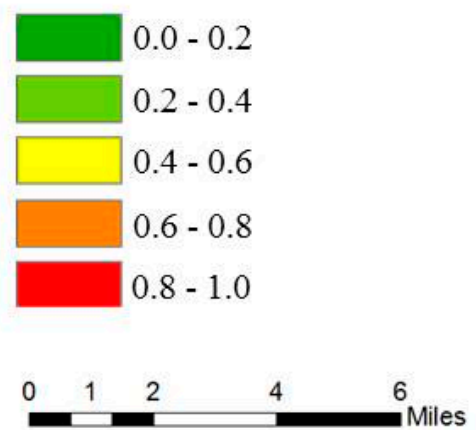

Figure 2. Debris risk map of Namaxia District. 


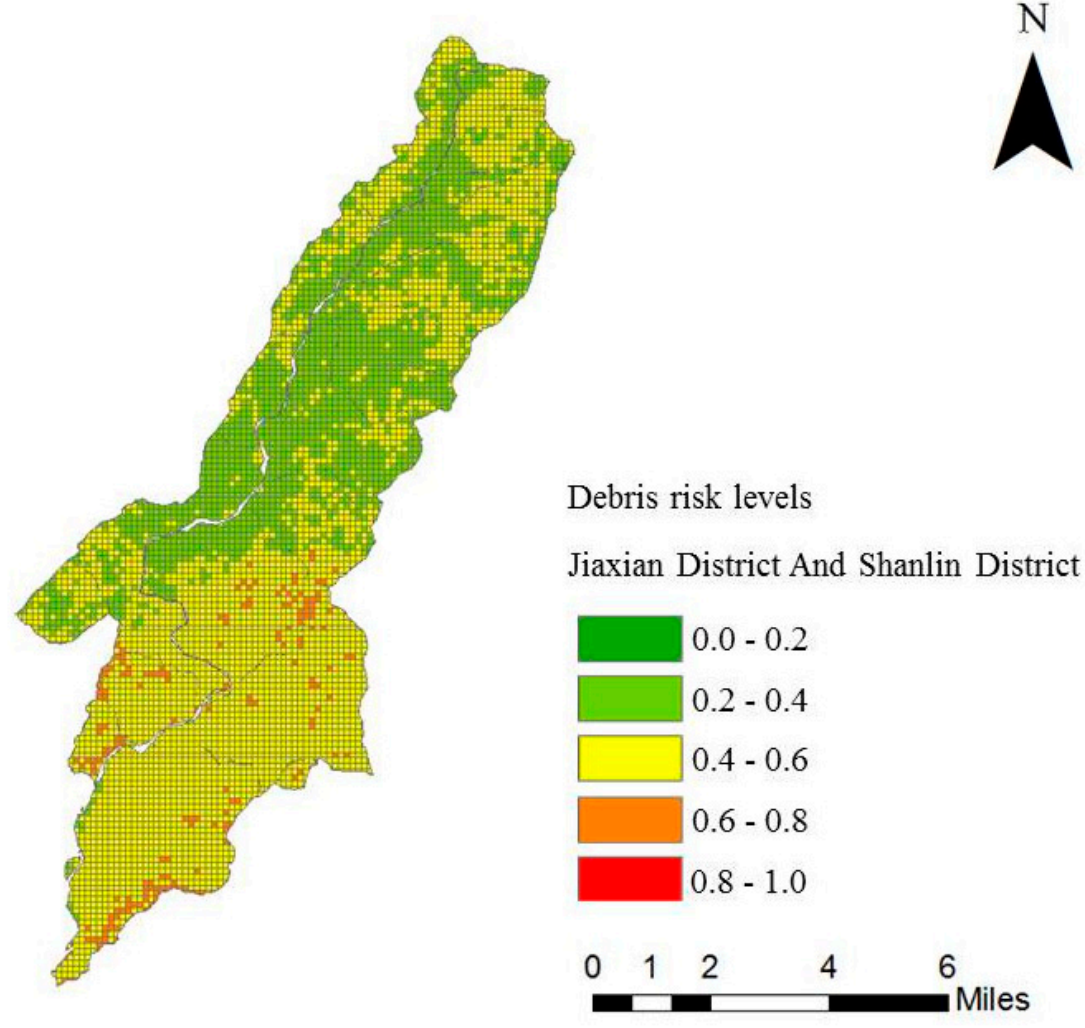

Figure 3. Debris risk map of Jiaxian District and Shanlin District.

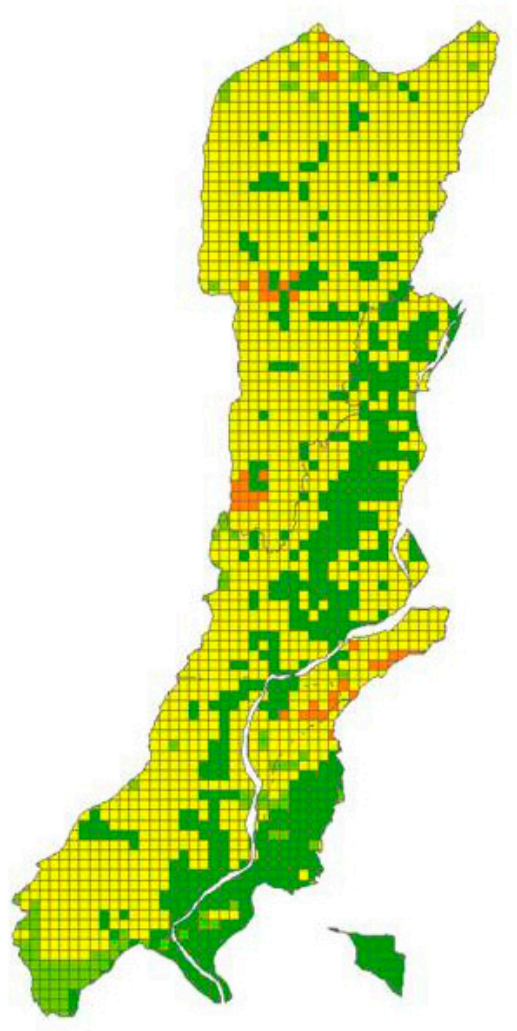

Debris risk levels

Qishan District And Neimen District

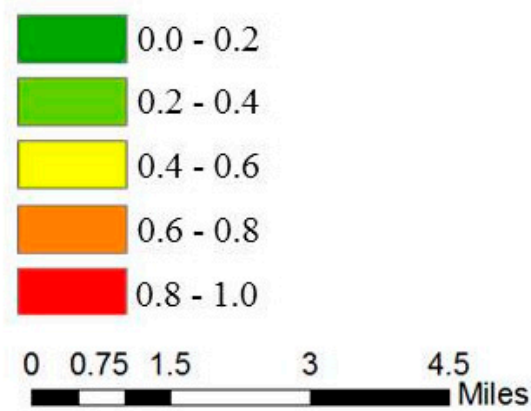

Figure 4. Debris risk map of District District and Neimen District. 


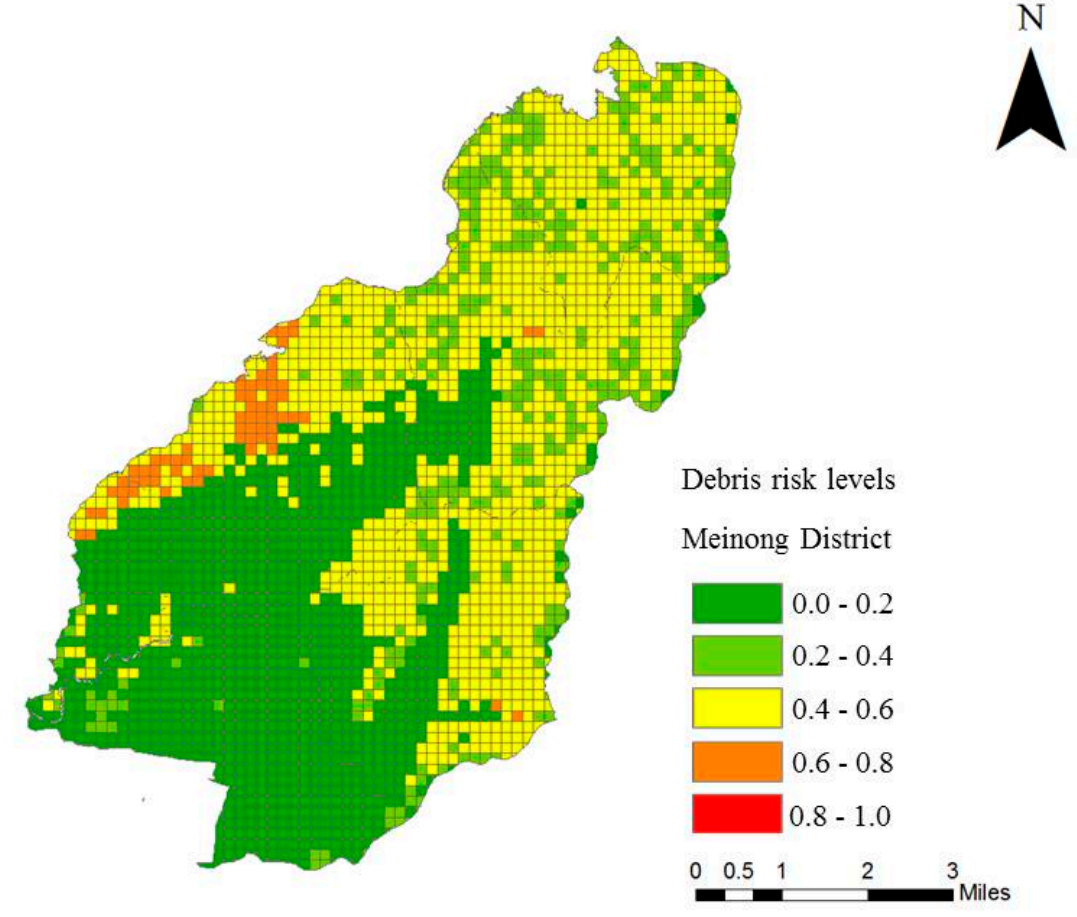

Figure 5. Debris risk map of Meinong District.

Figure 6 presents a potential land-slide disaster value map produced by the National Science and Technology Center for Disaster Reduction (NCDR); in this map, color patterns indicate both land use intensity and risk vulnerability; the deeper the color is, the higher the potential for disaster in that location. The potential debris flow map matches the debris risk maps proposed in this study (Figures 1-5).

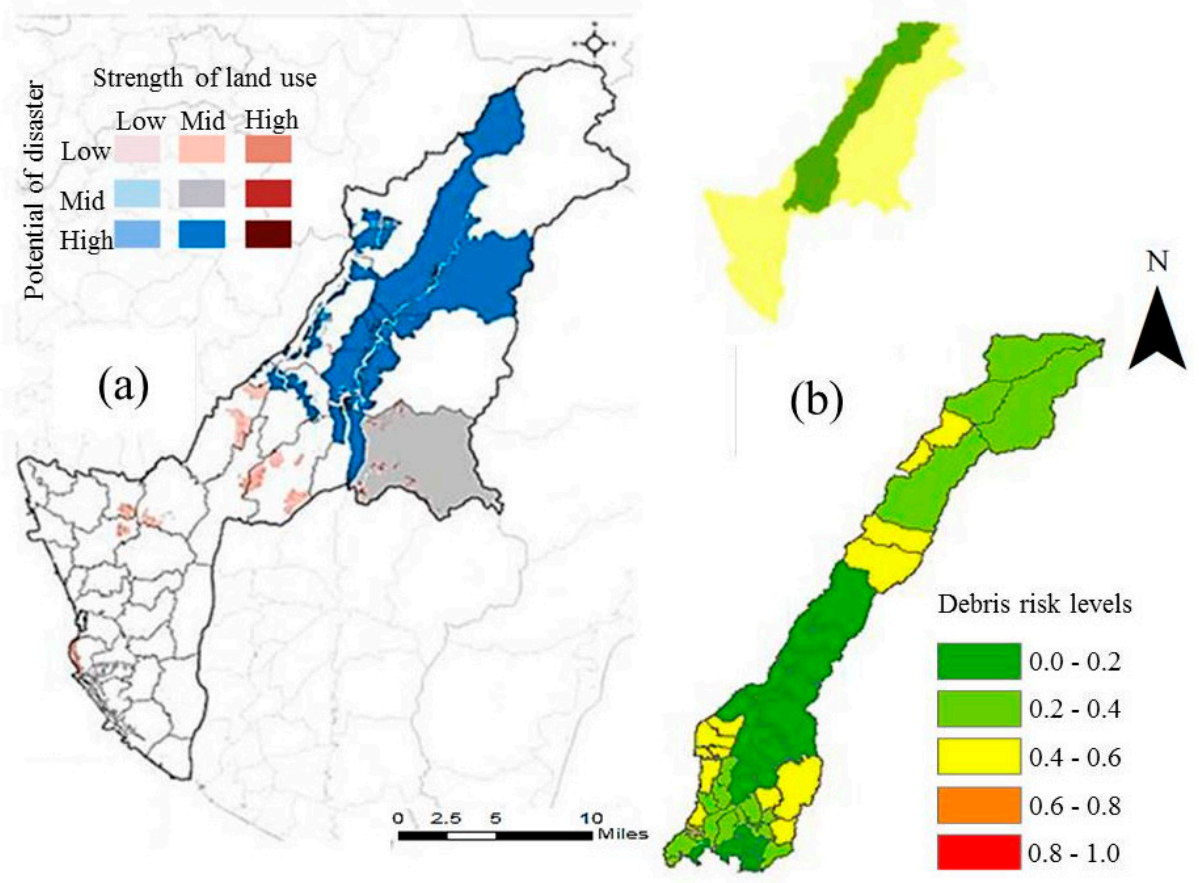

Figure 6. Comparison between (a) Debris risk map of National Science and Technology Center for Disaster Reduction (NCDR, 2013) and (b) Debris risk map proposed in this study. 
Figure 7 shows a risk map based on the MHER risk assessment framework [7]. This risk map was plotted based on mitigation projects and evacuation facilities and routes. In Figure 7, yellow, orange, and red indicate median, high, and very high risk, respectively. In general, the pattern of Figure 7 matches that in Figures 1-5, except a higher risk was estimated in certain areas in Jiaxian District, which locates in the lower left hand side of Figure 7b, and also shown in Figure 3. This is because the MHER risk assessment framework designated most buildings in Jiaxian District as several decades old and, therefore, high-risk buildings. The conditions of the buildings were not considered in this study.

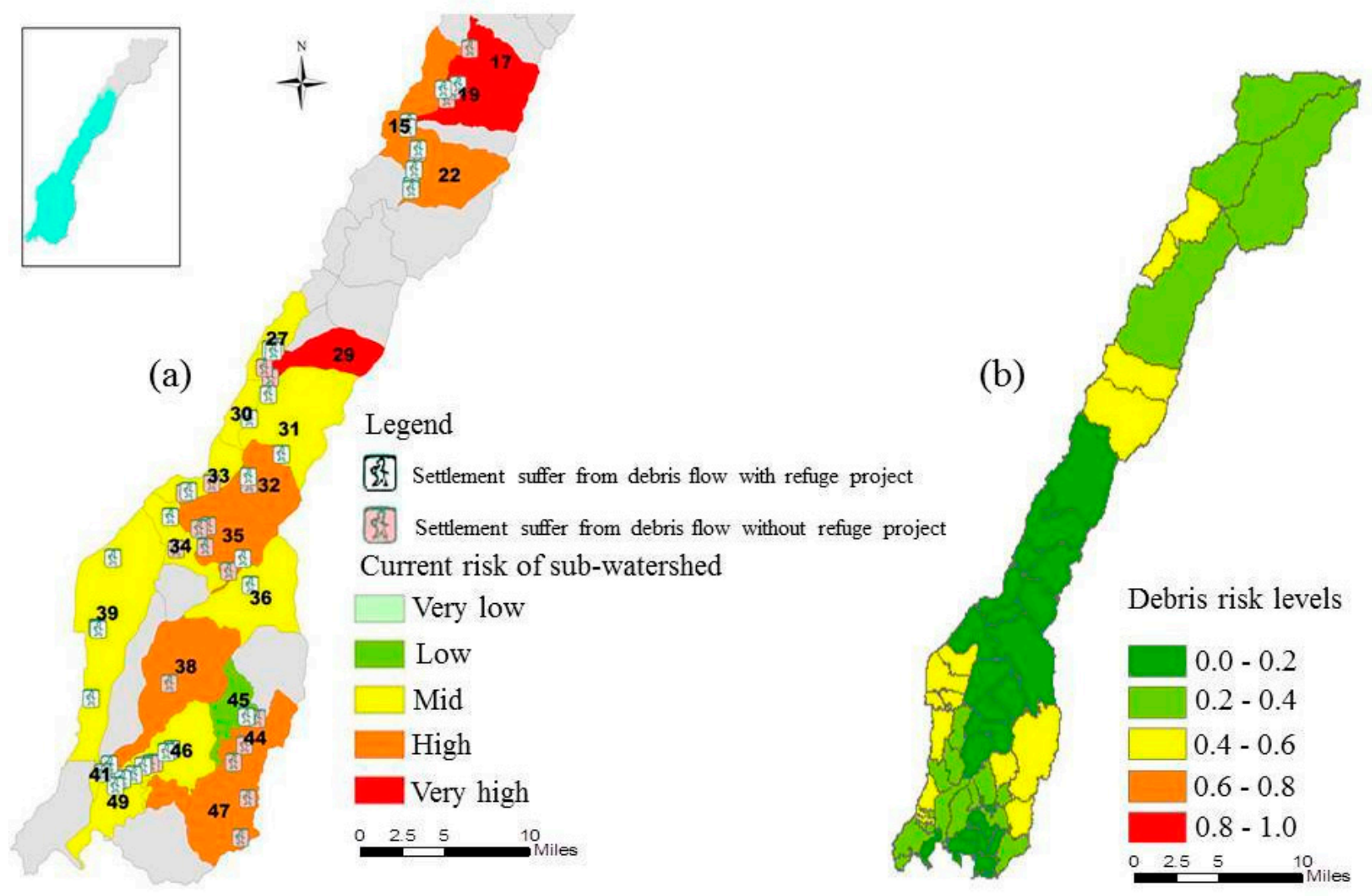

Figure 7. Comparison between (a) Debris risk map produced based on MHER risk assessment framework, 2011 [7] and (b) Debris risk map proposed in this study.

\subsection{Flood Risk Analysis}

Figures 8-12 depict the flood risk maps of the study area. The flood risk in Chishan basin was low, exhibiting a value between 0 and 0.2 , mainly because the area is located upstream of the Kaoping river at a high altitude. Water in this basin area flows rapidly. Only approximately $3.52 \mathrm{~km}^{2}$ of the basin reached medium flood risk.

Figure 13 shows a flood risk assessment map plotted by a government agency. This map combines a potential flooding map and a land use intensity map. Figure 13 indicates a negligible flood risk in the Chishan basin. 


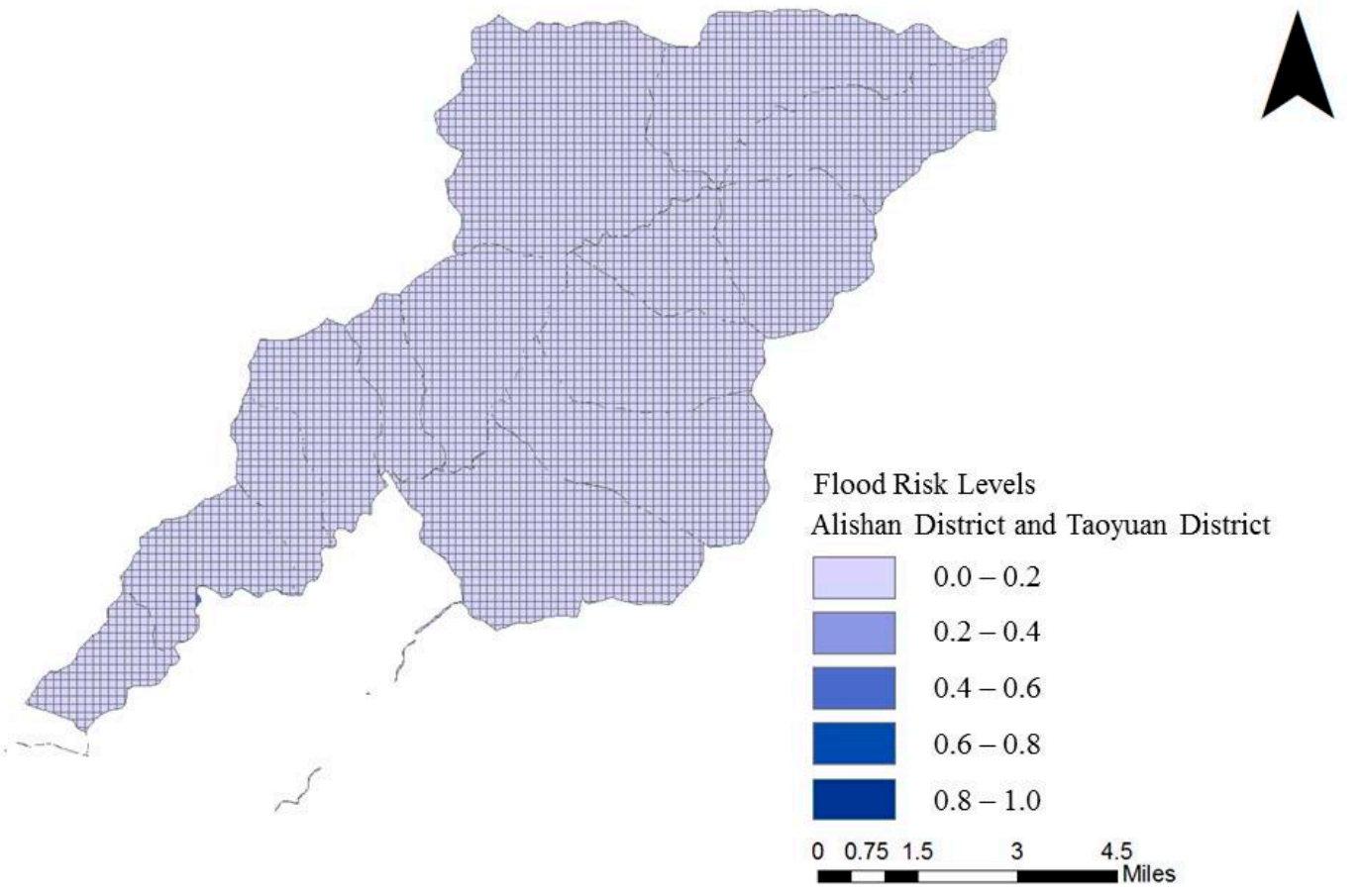

Figure 8. Flood risk map of Alishan District and Taoyuan District.

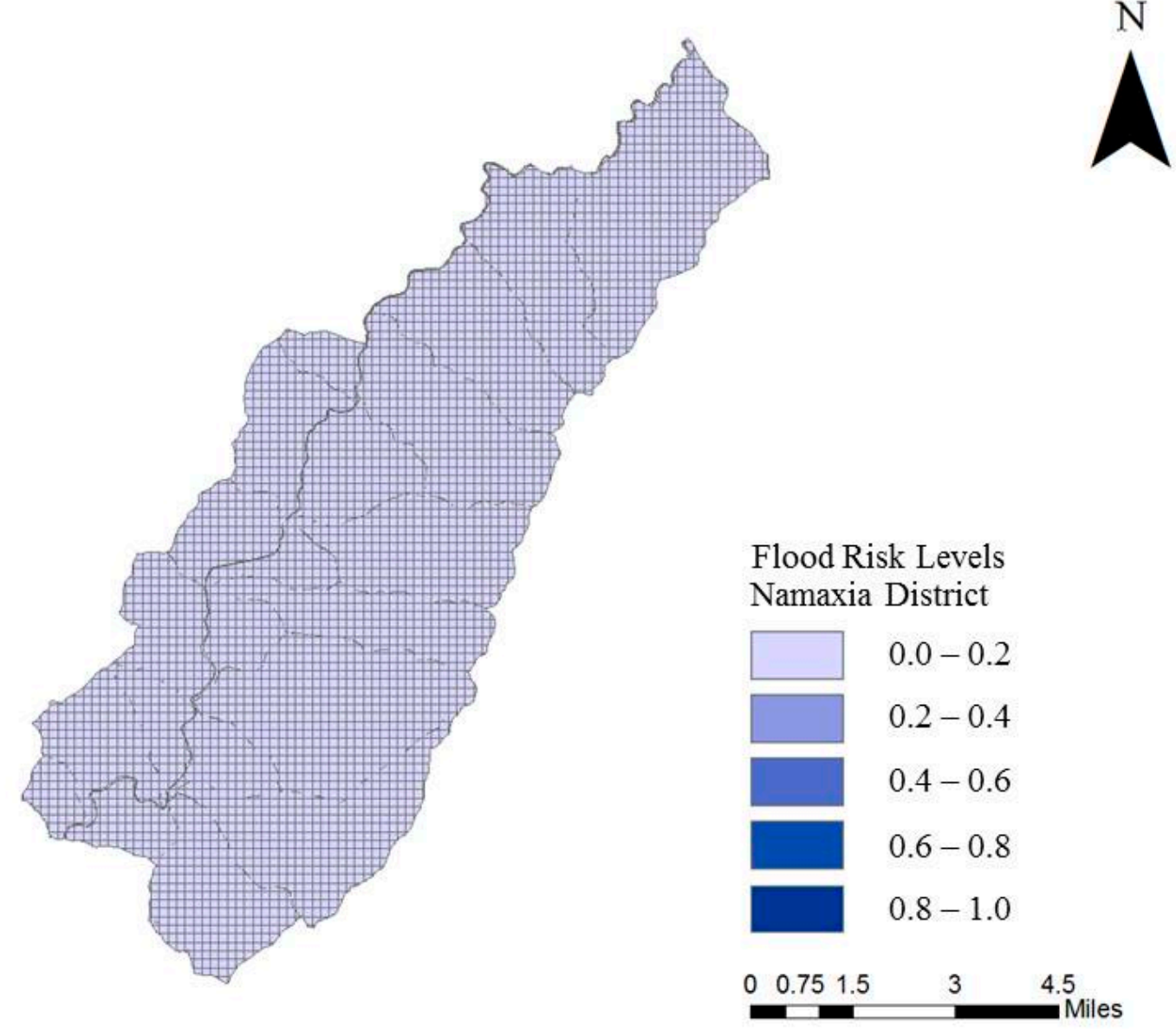

Figure 9. Flood risk map of Namaxia District. 


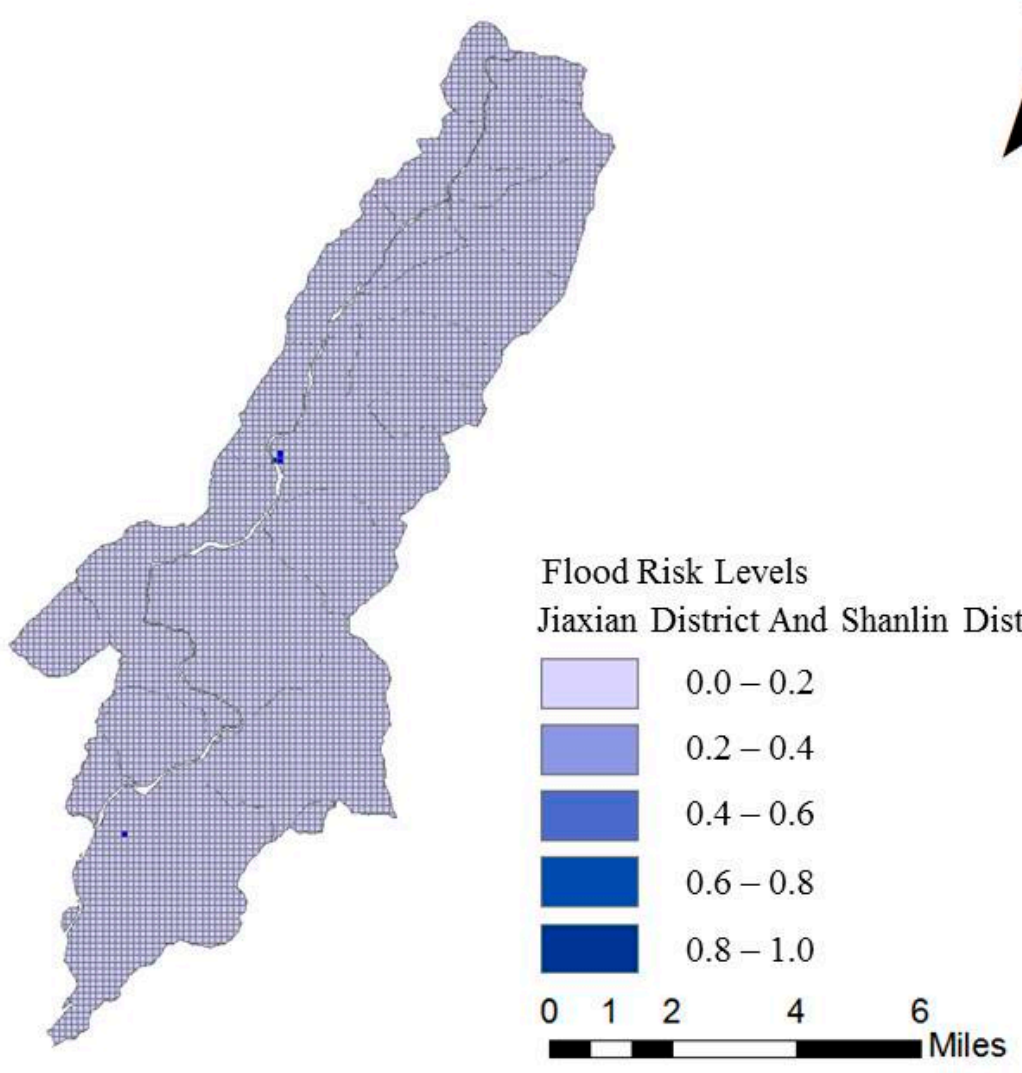

Figure 10. Flood risk map of Jiaxian District and Shanlin District.

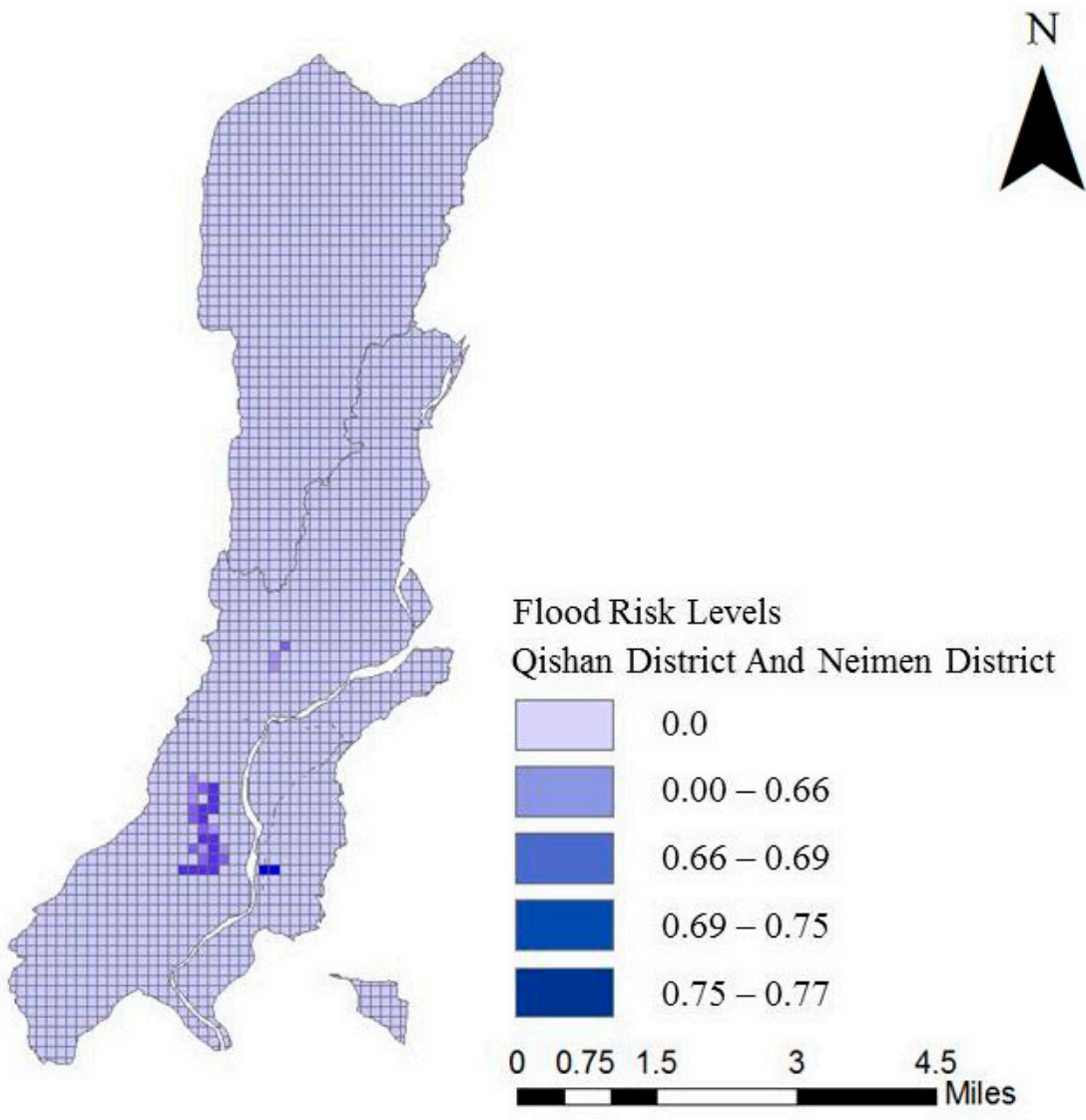

Figure 11. Flood risk map of Qishan District and Neimen District. 


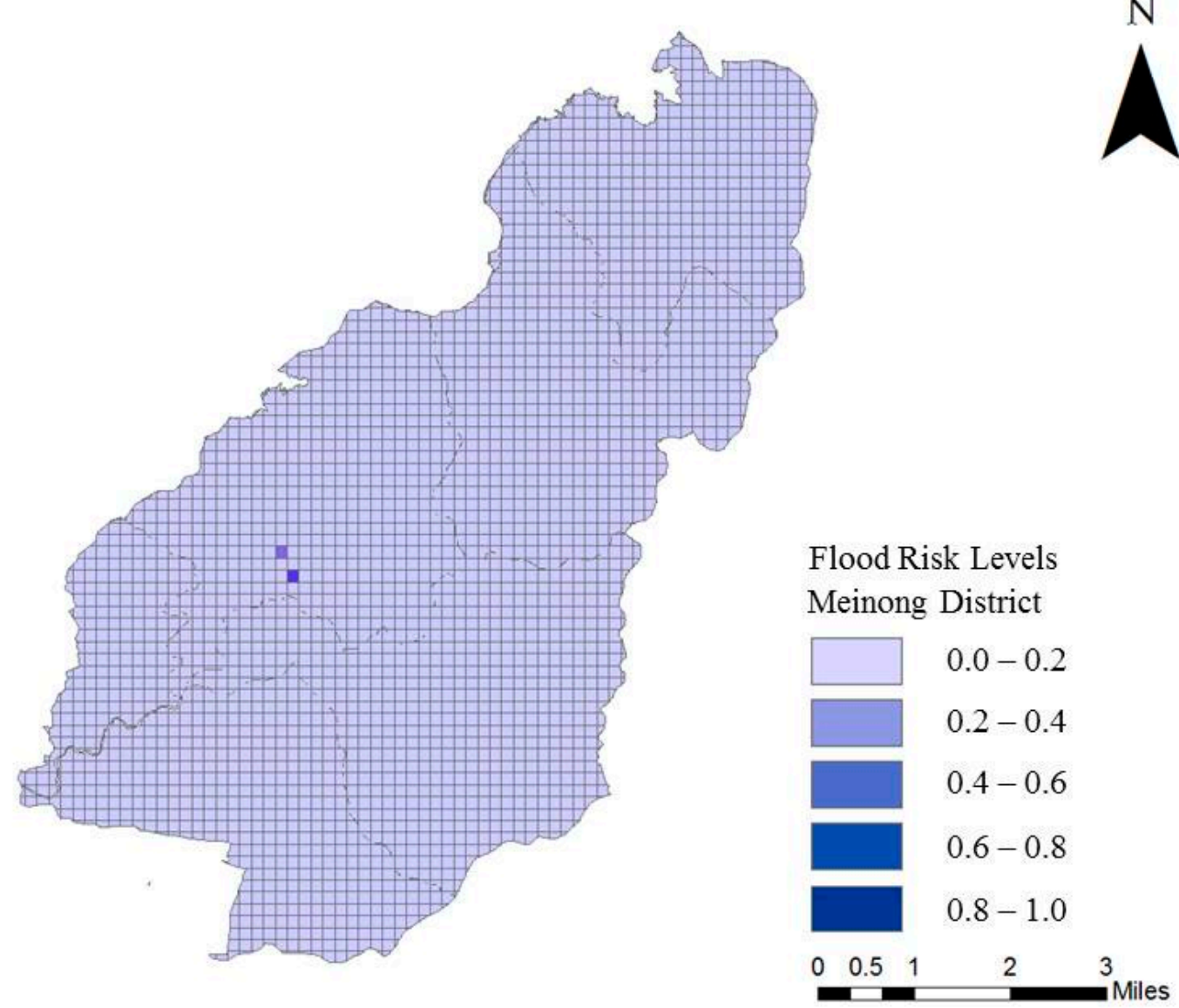

Figure 12. Flood risk map of Meinong District.
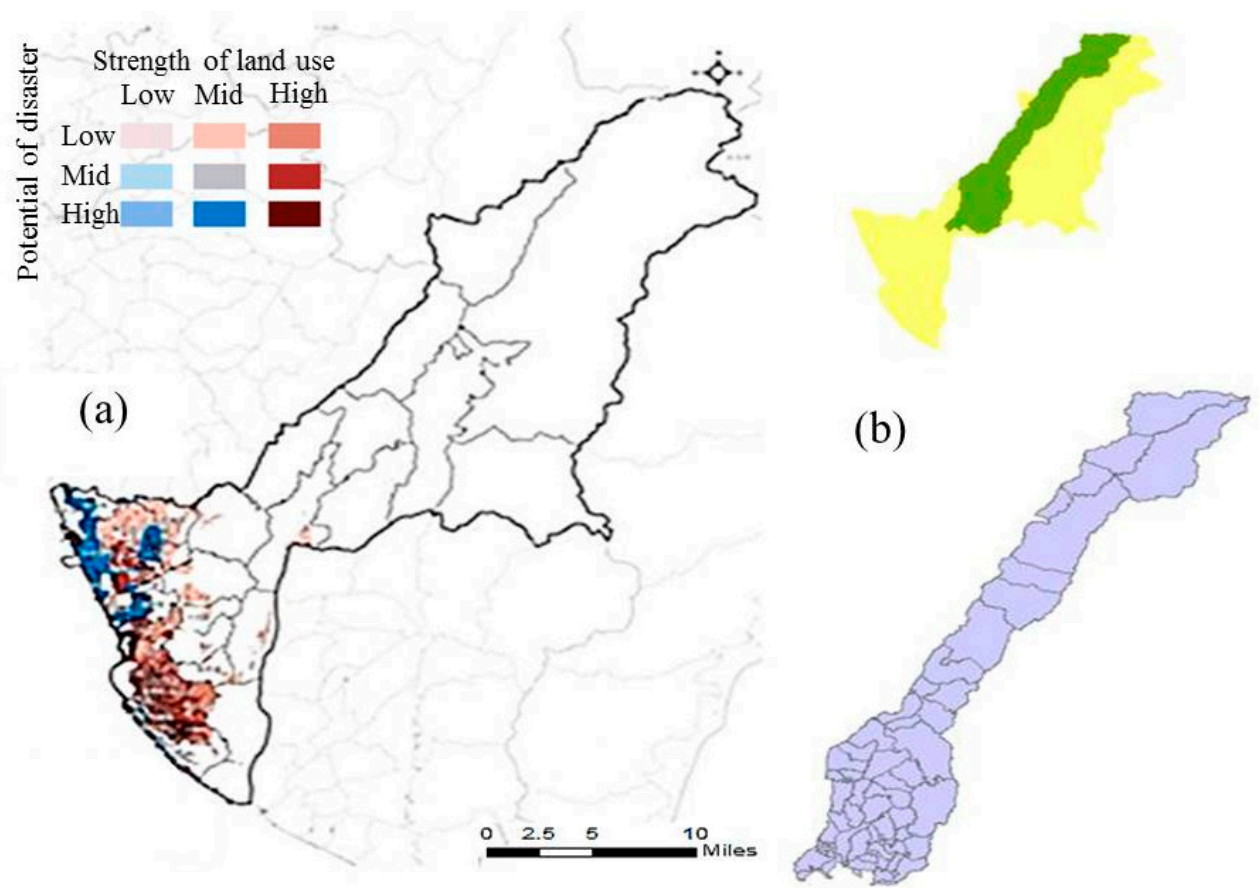

Figure 13. Comparison between (a) flood risk map of Kaohsiung of NCDR, 2013 and (b) flood risk map proposed in this study. 


\subsection{Drought Risk Analysis}

Figures 14-18 depict the drought risk maps of the study area. In general, the drought risk is low in the Chishan basin because both the population and agricultural water demand are low. Factories that require a high amount of water per unit area are only located in a few areas. The water risk maps of the Qishan and Meinong Districts show that some locations exhibit a low median risk of water scarcity. The factories in the Meinong District are more widely distributed than those in the Qishan District.

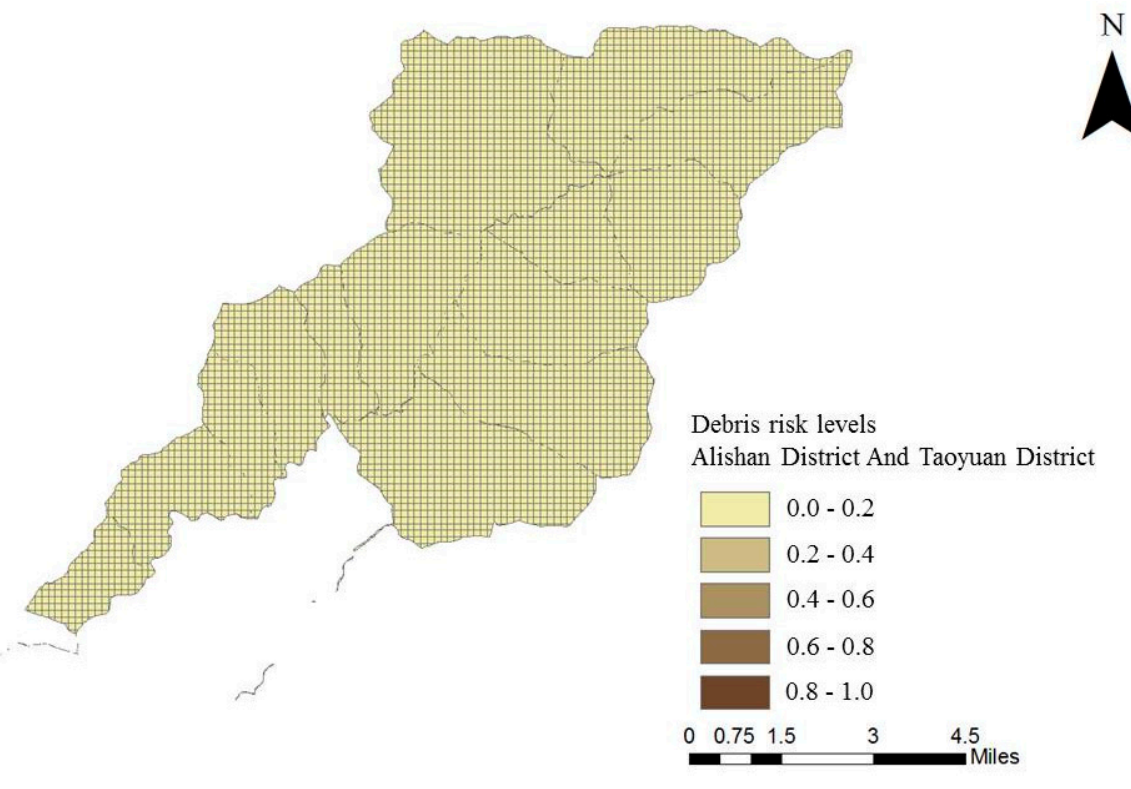

Figure 14. Drought risk map of Alishan District and Taoyuan District.

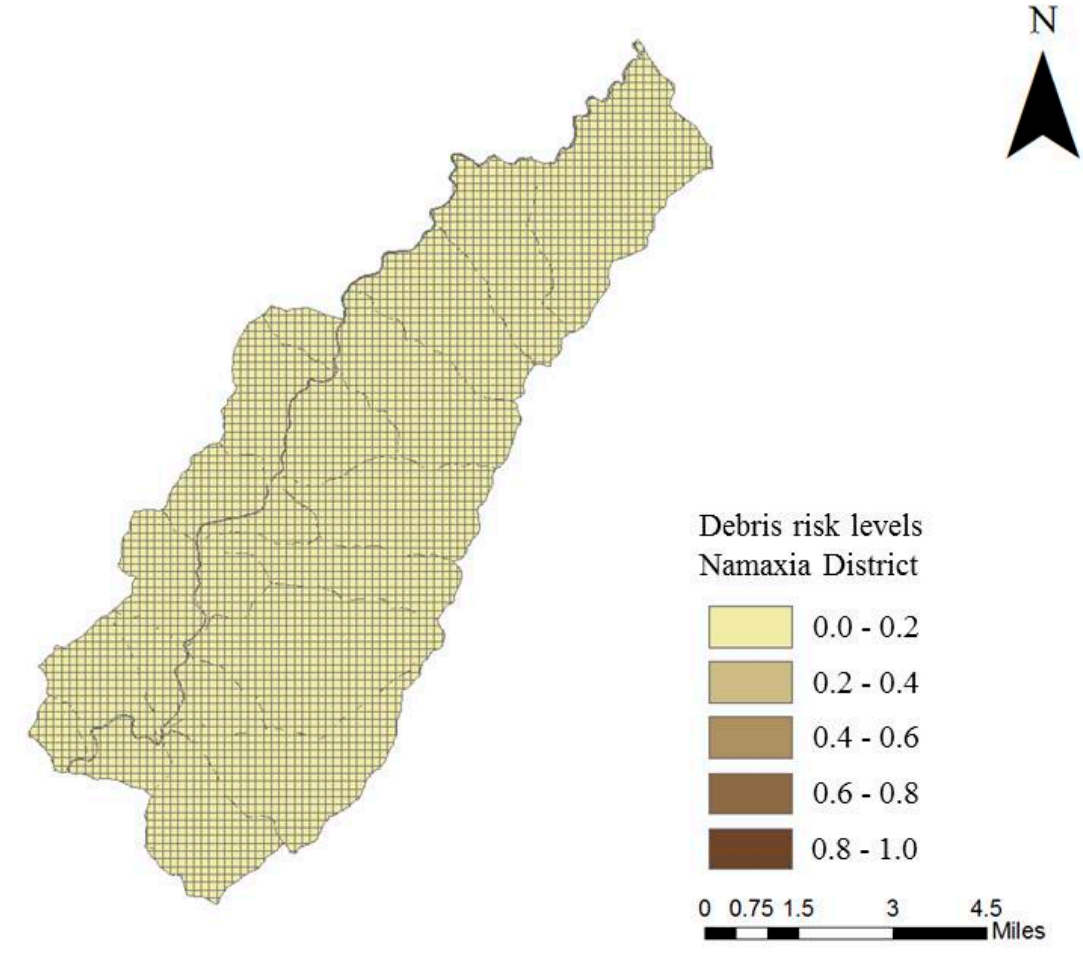

Figure 15. Drought risk map of Namaxia District. 


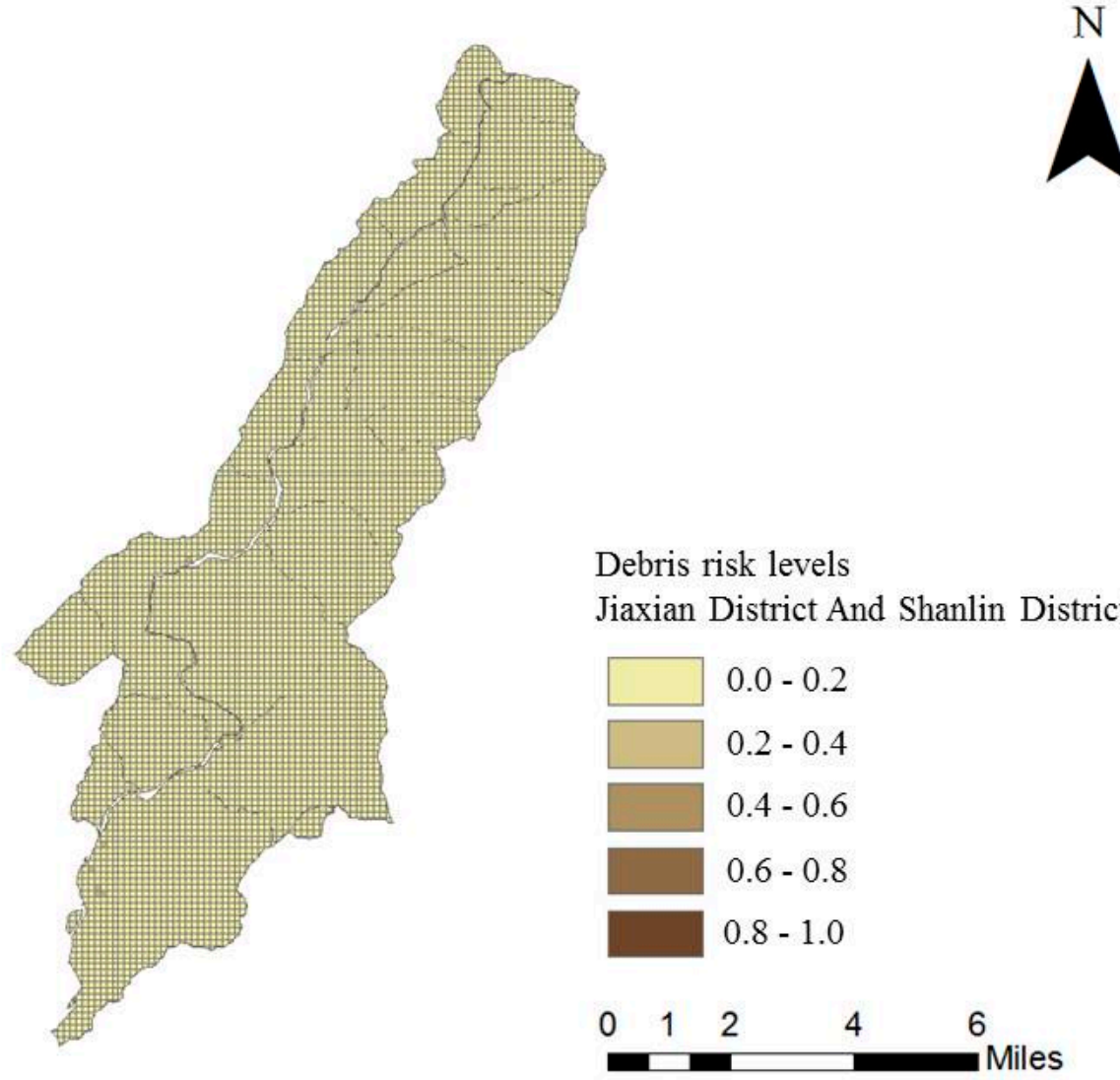

Figure 16. Drought risk map of Jiaxian District and Shanlin District.
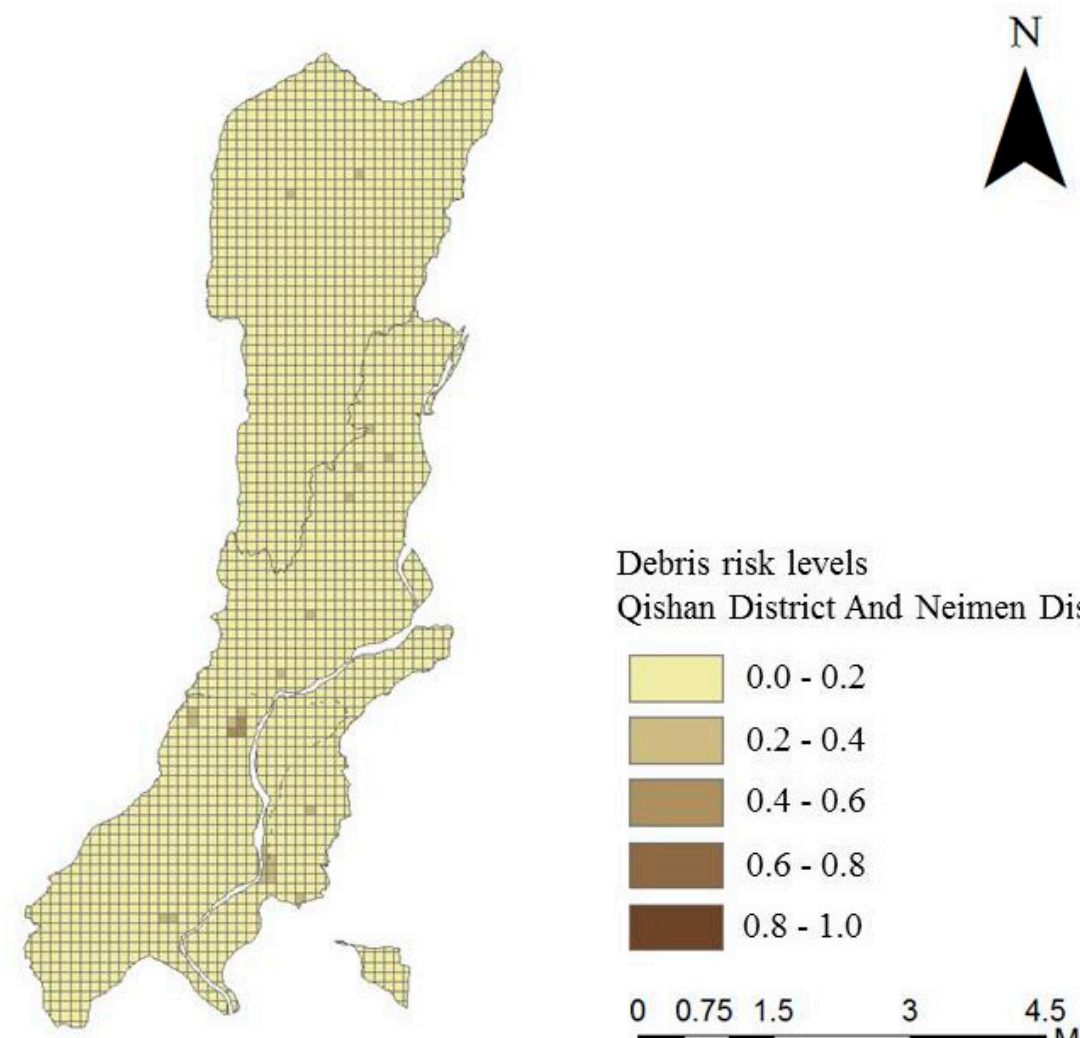

Debris risk levels

Qishan District And Neimen District

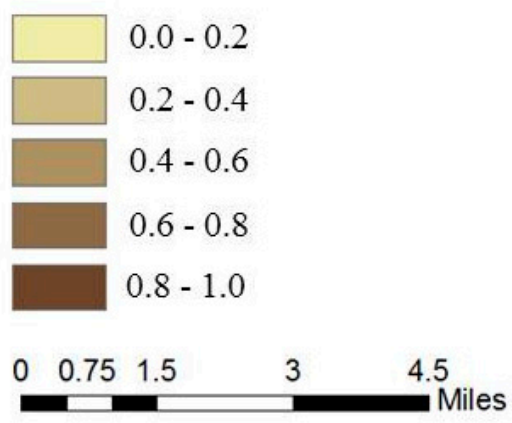

Figure 17. Drought risk map of Qishan District and Neimen District. 


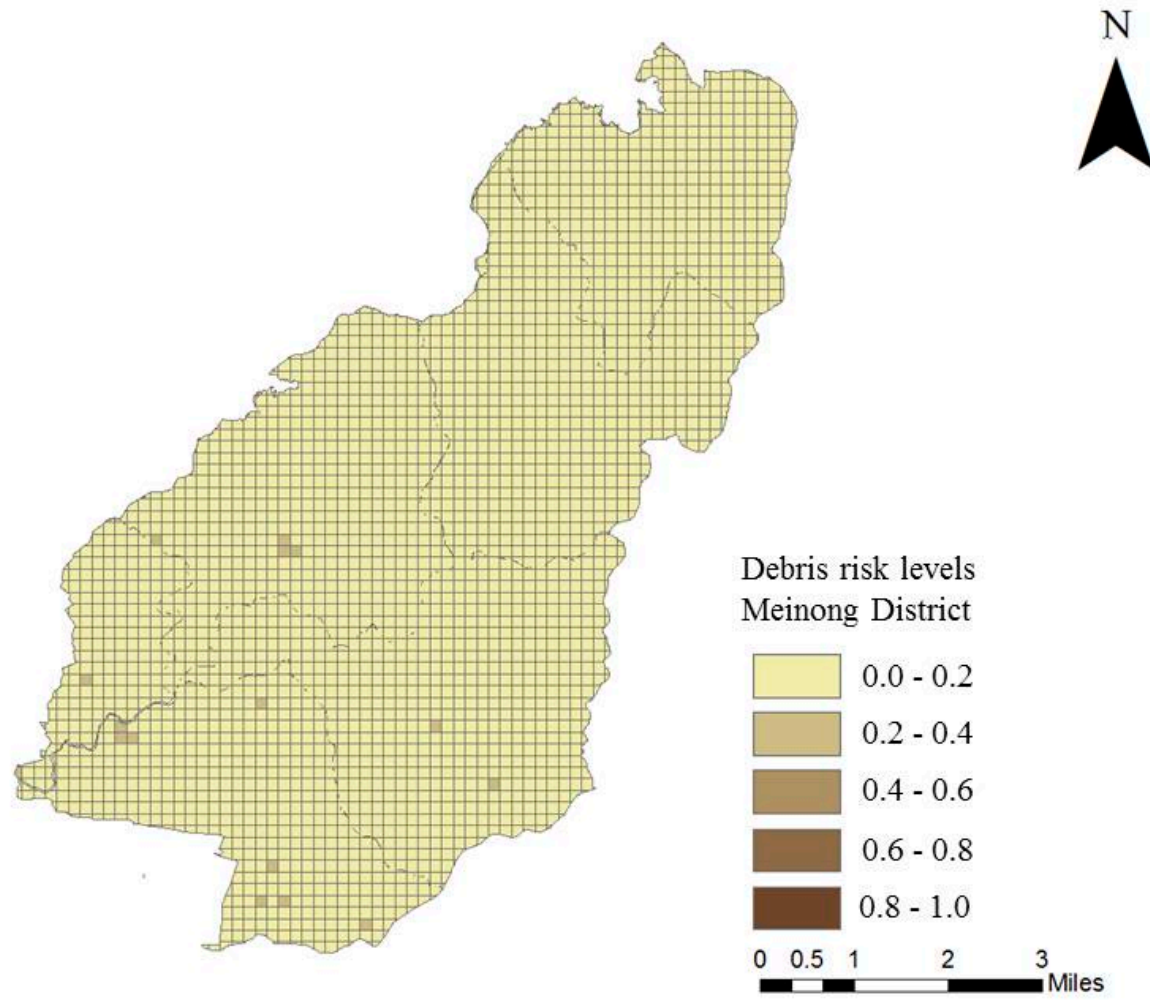

Figure 18. Drought risk map of Meinong District.

Figure 19 depicts a risk map of water resources in Kaohsiung City produced by the Water Resources Planning Institute of the Water Resources Agency. The map shows that, in the Chishan basin, the Qishan, Neimen, and Meinong Districts exhibit the highest risk of drought. This observation is consistent with a finding of this study, as shown in Figures 14-18.

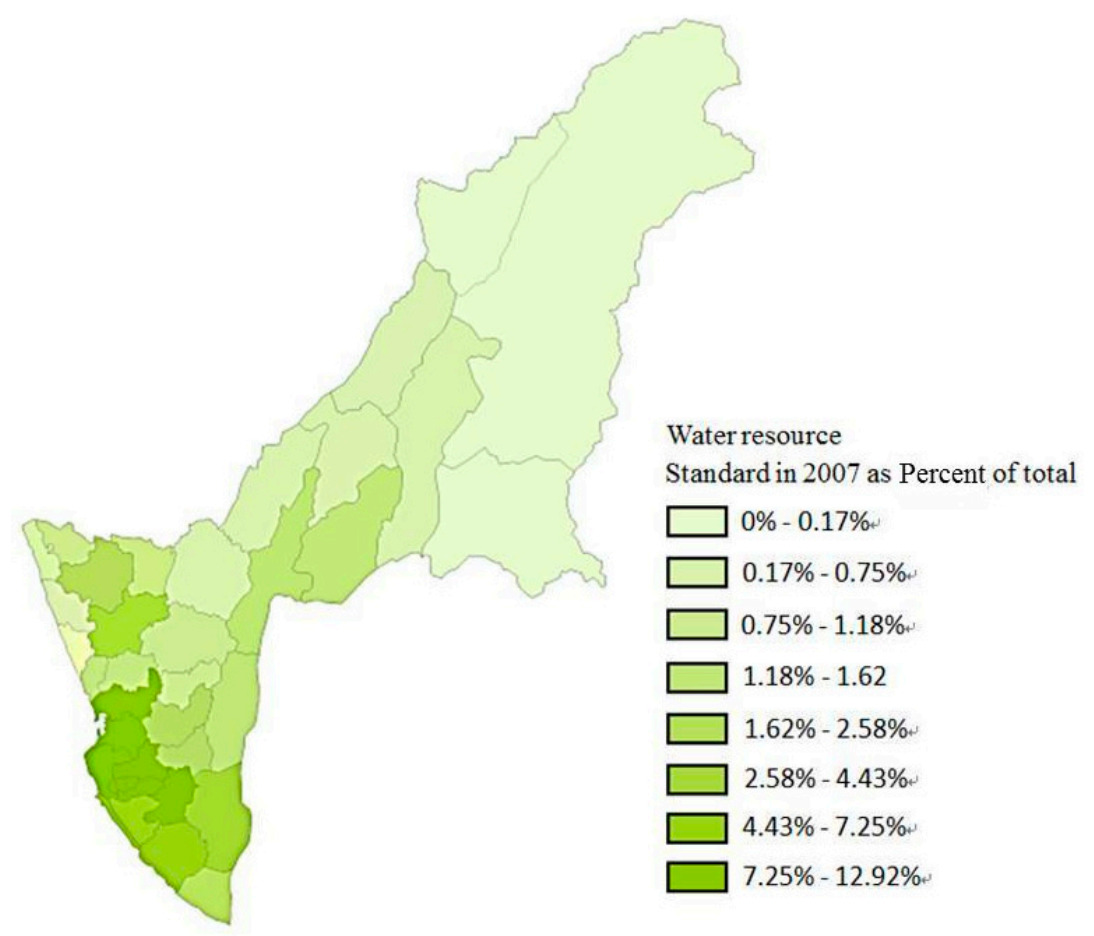

Figure 19. Drought risk map of drought in Kaohsiumg City. 


\subsection{Risk Analysis of Xiaolin Village and Evaluation of Relocation}

Xiaolin village is located in the northeast of Jiaxian District. During Typhoon Morakot on 8 August 2009, the settlement was completely destroyed. A total of 630 residents lived in Xiaolin village before the disaster. Of these, approximately 90 families remained, and 180 families relocated to either Shangping or Yuemei village. The relocation of Xiaolin village was examined in this study, and the difference between the risk at the original location of the village and that at the relocation site was evaluated. Figure 20 shows that the debris flow risk in Shangping village and Yuemei village, marked in red, is 0.5598 (i.e., moderate risk). Furthermore, Figure 21 shows that the debris flow risk at the original Xiaolin village site is 0.3981 (i.e., moderate and low risk). Therefore, the original site is relatively safer regarding debris flow.

Figure 22 shows that the flood risk in Shangping village and Yuemei village, marked in red, is negligible. That is, the whole area was free from floods, even in heavy rain. Similarly, Figure 23 shows that the flood risk of the original Xiaolin village site is negligible because it has an adequate drainage system. Therefore, the average flood risk for each of the sites is considerably low.

Figure 24 shows that the drought risk of Shangping village and Yuemei village, marked in red, is 0.1168 . Figure 25 shows that the flood risk of the original Xiaolin village site is 0.0495 . Despite the slight difference, and although the original Xiaolin village site exhibits a slightly lower risk of drought, both sites exhibit a low risk of drought.

In general, these three types of risk map can be integrated into a single risk map as a whole to evaluate the decision on the relocation of the village. However, no guideline is available for the relative weighting factors for each risk category, which are essential in the integrating of these three categories. Any arbitrarily picked factors cannot be justified. However, in this specific case, the principle of Pareto optimality is adapted to draw the conclusion. Given the fact that Flood risk and drought risk are both low and not significantly different for these two sites, the only criteria would be debris flow risk, which is relatively high in the relocation site. It is concluded that the original Xiaolin village site should be rebuilt.

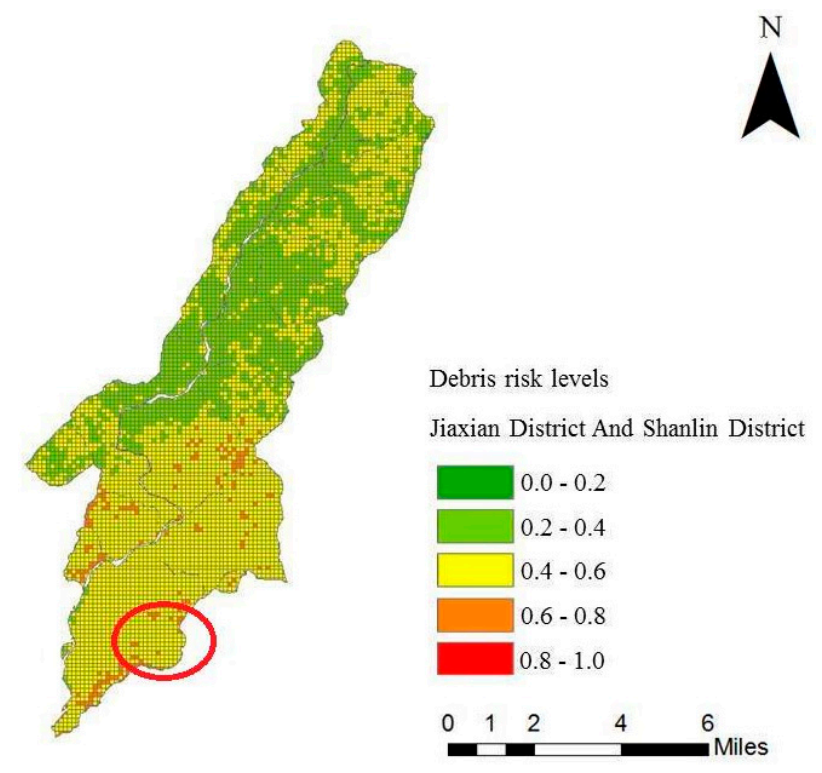

Figure 20. Debris risk map of relocated Shangping village and Yuemei village. 


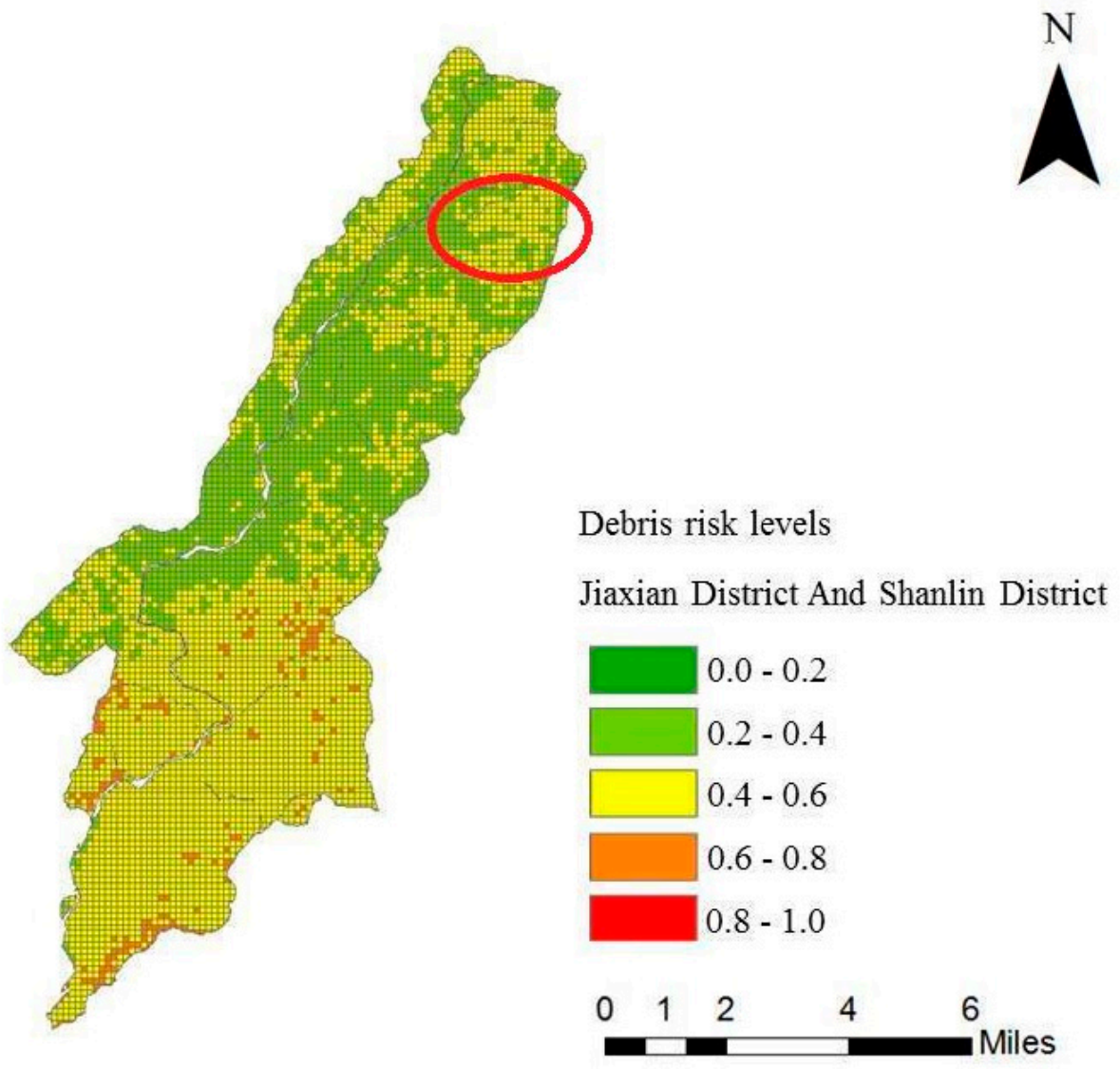

Figure 21. Debris risk map of original Xiaolin village site.

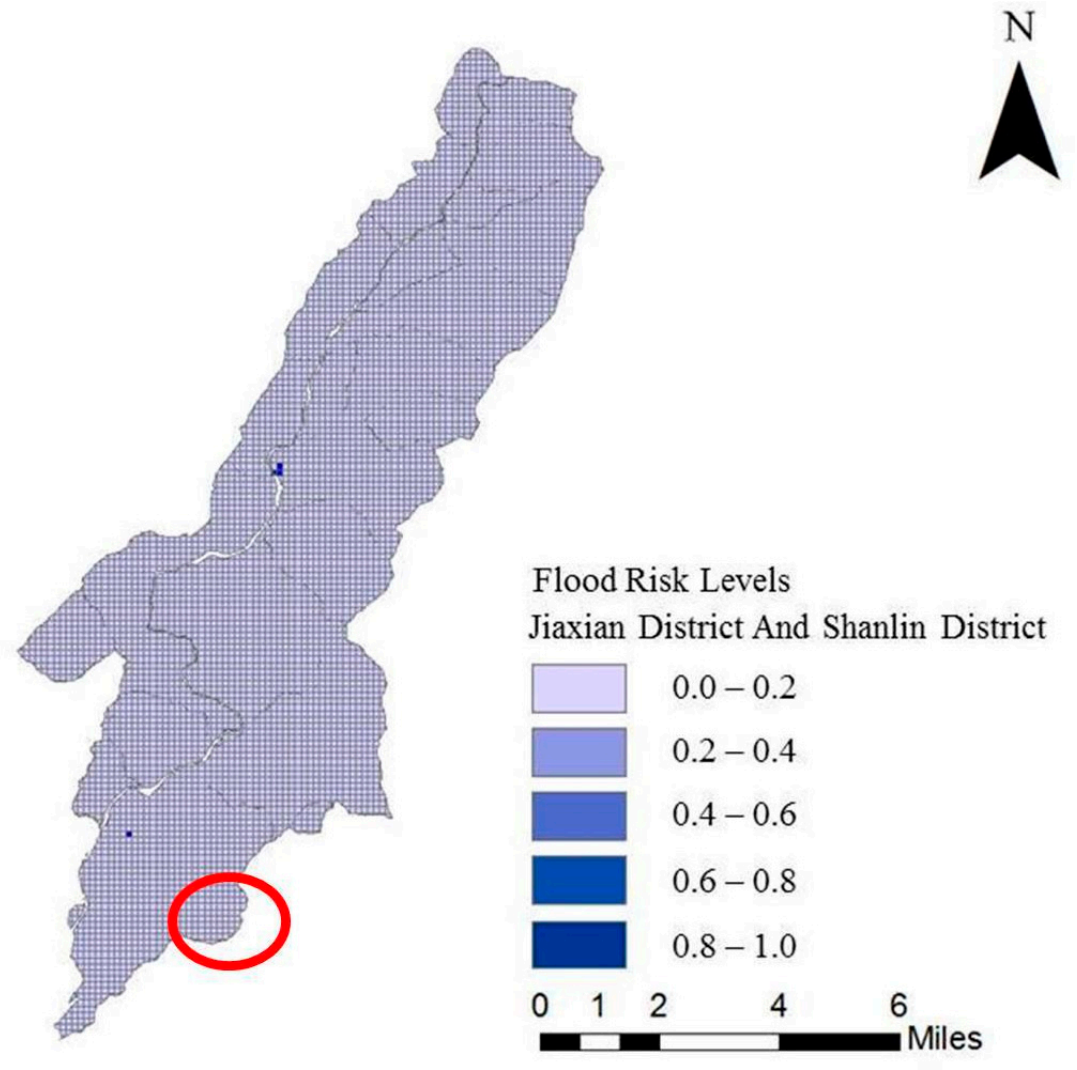

Figure 22. Flood risk map of relocated Shangping village and Yuemei village. 

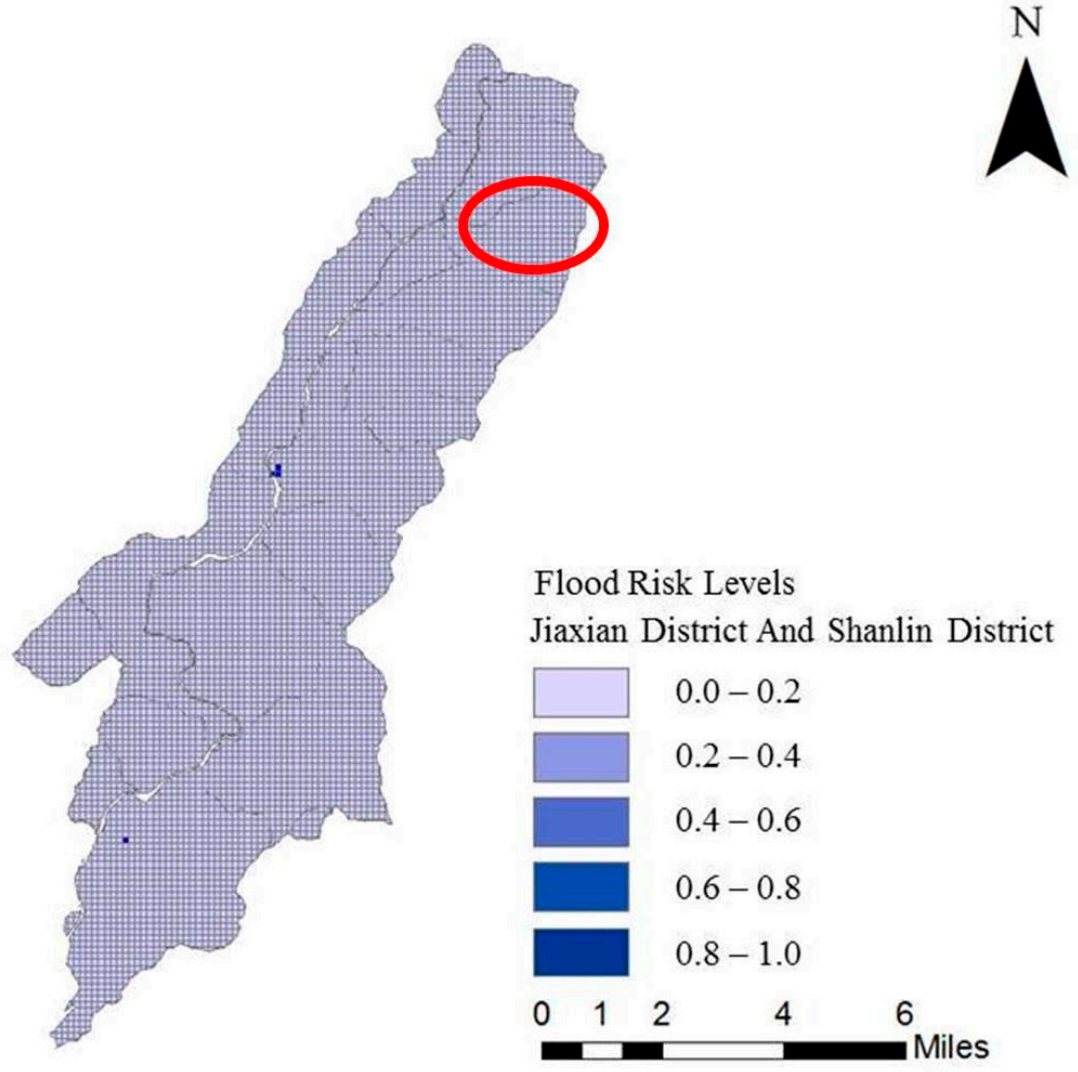

Figure 23. Flood risk map of original Xiaolin village site.
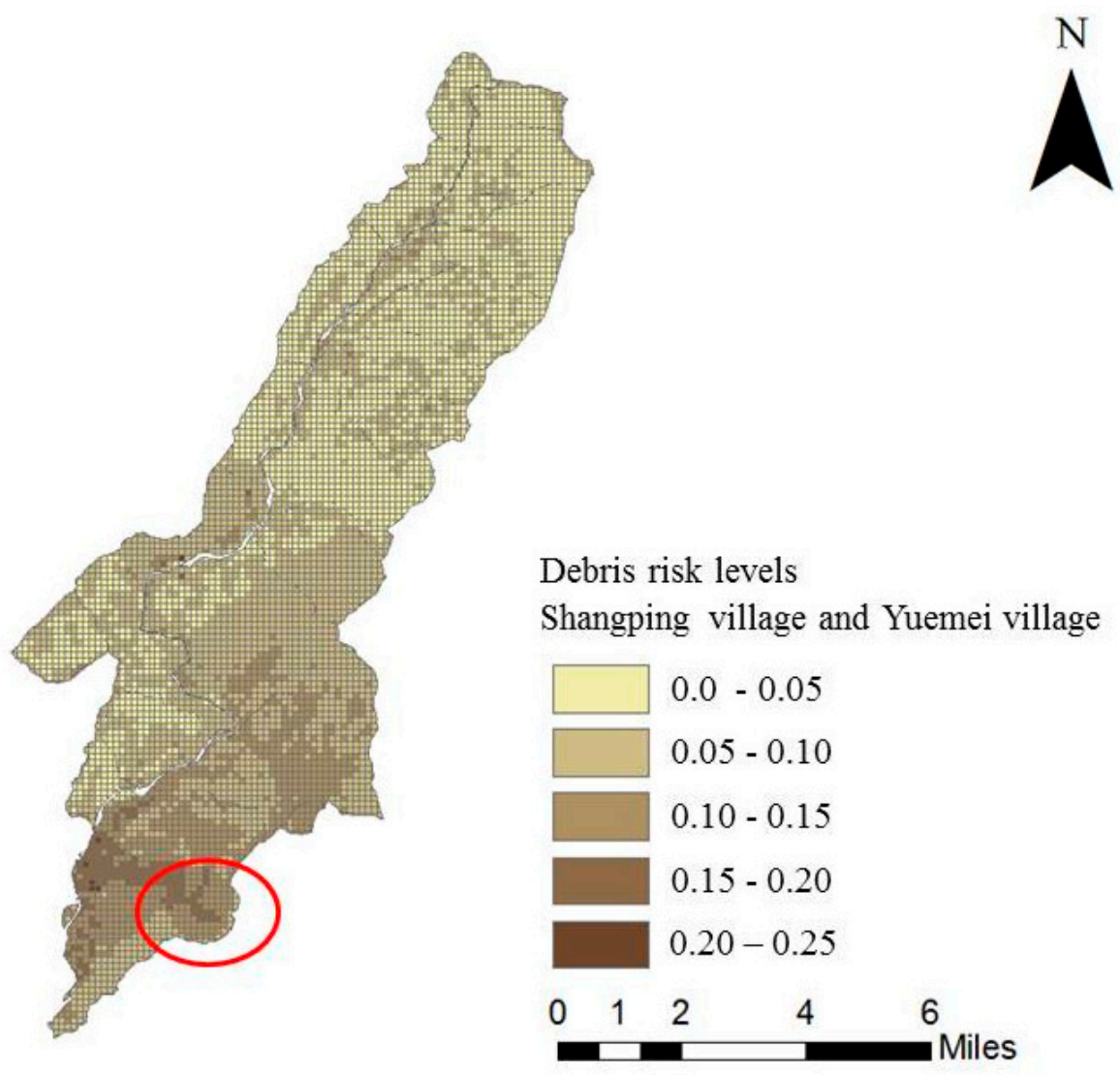

Figure 24. Drought risk of relocated Shangping village and Yuemei village. 


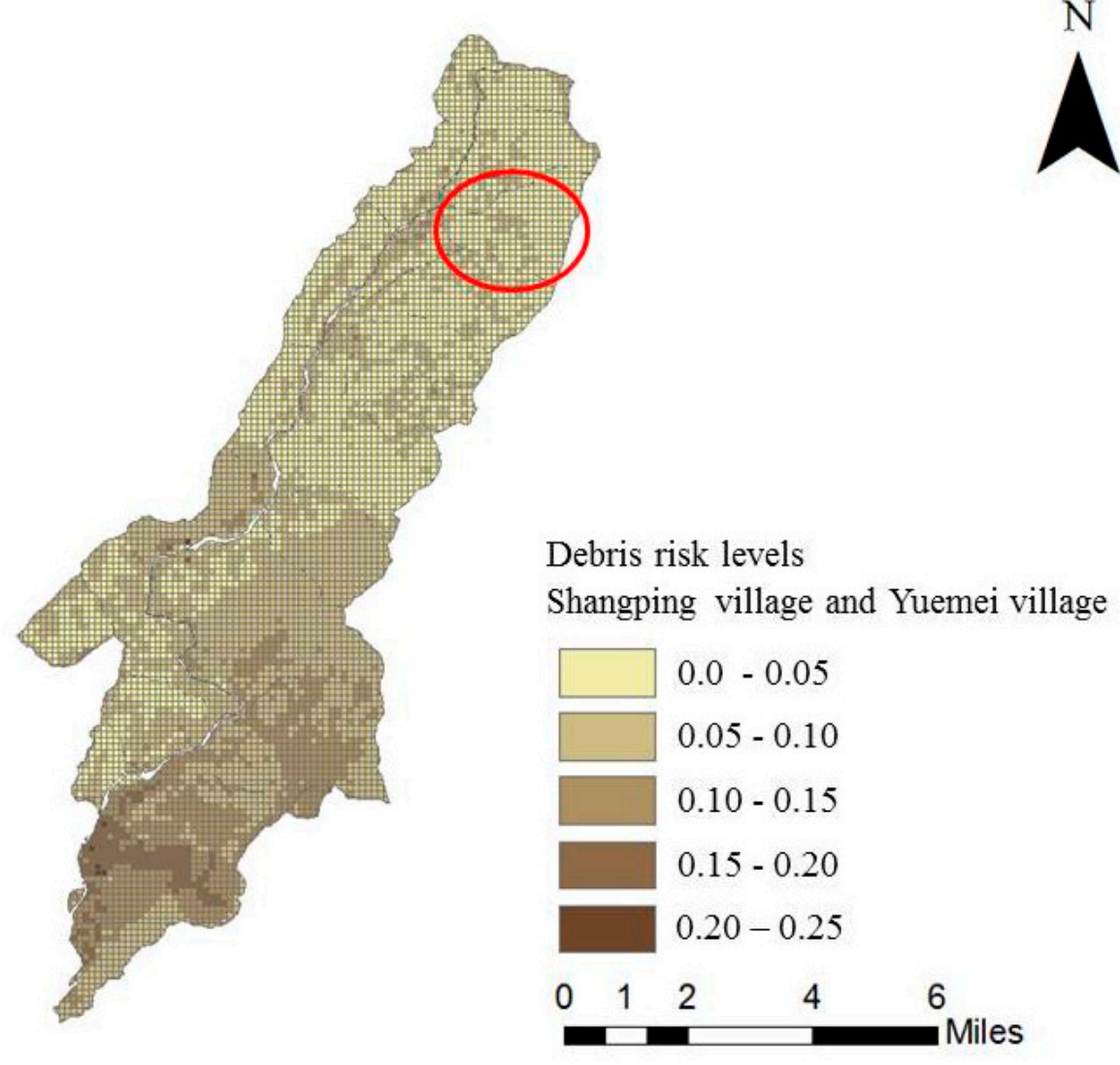

Figure 25. Drought risk map of original Xiaolin village site.

\subsection{Resilience Analysis}

This paper suggests incorporating resilience in risk assessment to address social and engineering aspects at the disaster recovery stage. To investigate the crucial role of resilience, two debris flow risk maps of the same area, one in which resilience was considered and one in which resilience was not considered, were compared, as shown in Figures 26 and 27. The debris flow risk decreased from 0.3734 to 0.3724 and 0.4712 to 0.4377 for Alishan District and Taoyuan District, and Chishan District and Neimen District, respectively. The reason that there was no substantial reduction of the debris-flow risk in Alishan District and Taoyuan District was that the effort exerted in disaster remediation in this region was negligible. By contrast, because of the investment in road development and a generous allocation to disaster relief resources in Chishan and Neimen Districts, the risk was reduced from 0.4712 to 0.4377 . The reduction of risk caused by improving resilience can be employed in tools to evaluate the benefit of disaster remediation measures or investments. The results of this study indicated that the development of densely populated or urban areas is usually accompanied by the deployment of disaster prevention and rescue resources. Compared with Alishan District and Taoyuan District, Chishan District and Neimen District are more densely populated. With the investment in disaster relief measures, Chishan District and Neimen District experiences greater reduction in the risk than that in Alishan District and Taoyuan District. Consequently, intensive development does not necessarily increase risk. By contrast, risk depends on the interaction, degree of exposure, and effort in improving resilience. In the Chishan and Neimen Districts, a high degree of exposure has been upset with the resilience, reducing the overall risks. Incorporating resilience in the 
assessment revealed that, the higher the exposure is, the higher the resilience becomes. In other words, hazards might not necessarily cause damage.

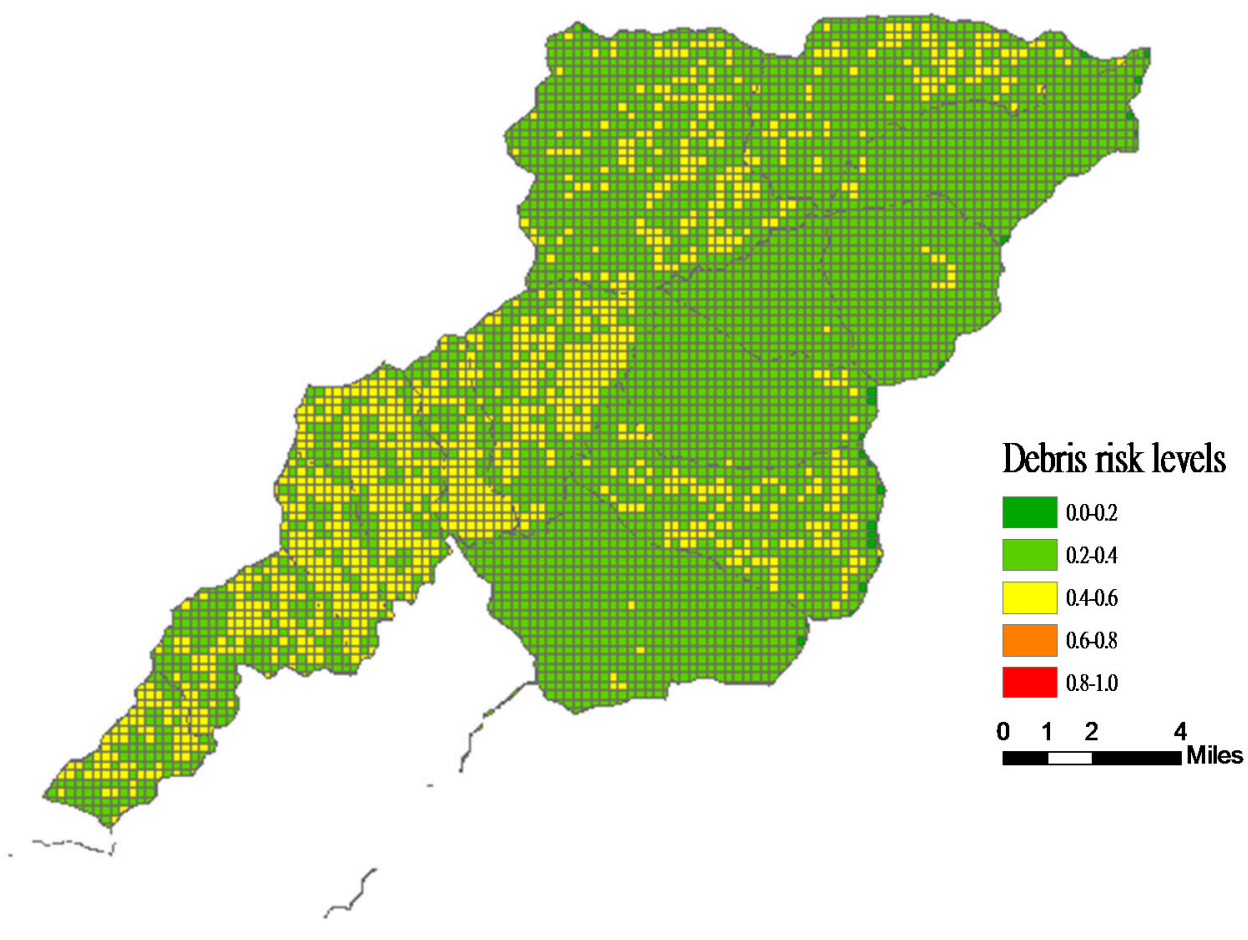

(a)

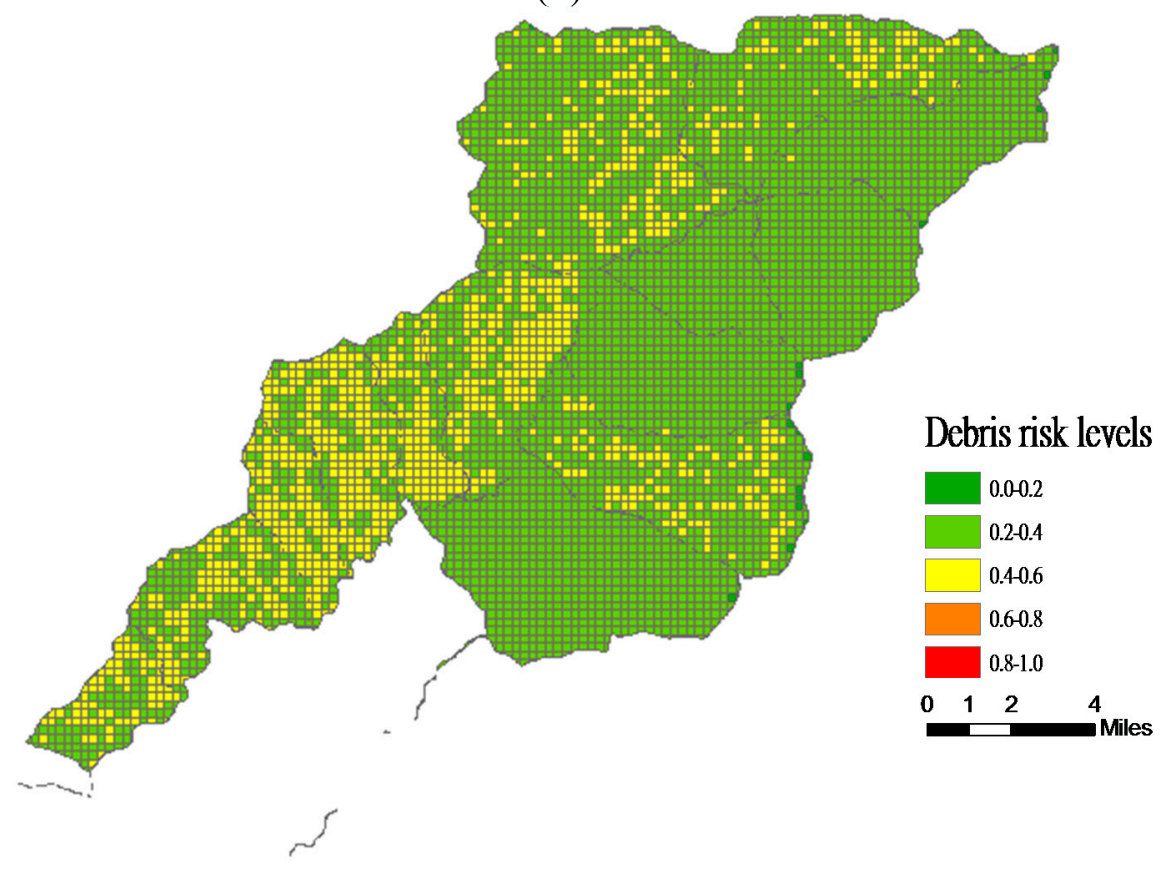

(b)

Figure 26. Debris flow risk maps of Alishan District and Taoyuan District: with and without resilience considered. (a) without resilience considered; (b) with resilience considered. 


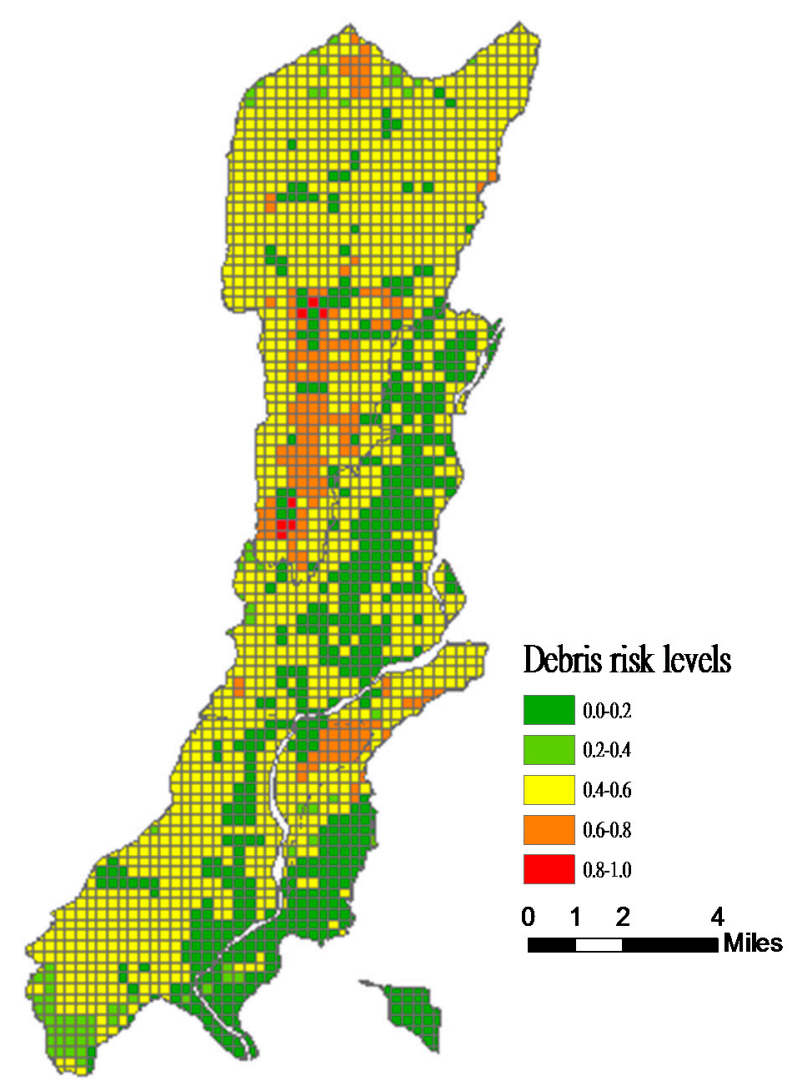

(a)

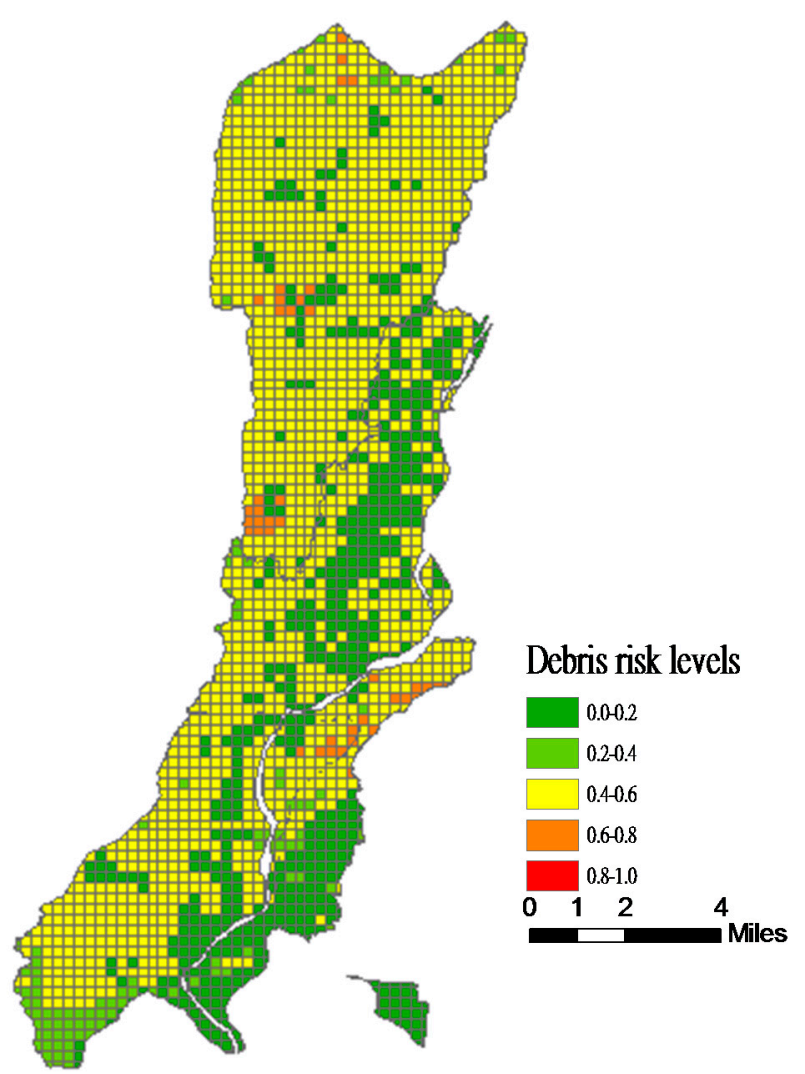

(b)

Figure 27. Debris flow risk maps of Chishan District and Neimen District: with and without resilience considered. (a) without resilience considered; (b) with resilience considered.

\section{Conclusions}

This study examined natural disasters, namely debris flows, floods, and droughts, in river basins by employing a system analysis approach. Four aspects were addressed, namely natural disaster reduction, hazard, exposure, and capacity. Each type of natural disaster has distinct assessment factors. The interactions of these factors should be considered in risk assessment as well as in monitoring and providing natural disaster warnings. The Chishan basin was examined in a case study, and the feasibility of relocating Xiaolin village was analyzed. The results are shown in a GIS containing grids with a resolution of $200 \mathrm{~m} \times 200 \mathrm{~m}$.

Incorporating resilience into the assessment revealed that the higher the exposure is, the higher the resilience becomes. This is because highly populated areas usually have adequate resources to respond to disasters. In other words, highly populated areas exhibit high resilience. The findings of this study enable decision makers to understand the urgent need to diversify the use of resources in areas of risk assessment. The relocation of residents requires the agency to identify whether adequate measures are taken to protect residents from high risk. This study demonstrates how to incorporate resilience in the analysis of the risk and provides the information for use of the allocation of disaster remediation resources. Resilience can be analyzed to elucidate the unique circumstances of a region affected by disaster and to determine whether the allocated resources are sufficient to respond to the disaster. 
In addition, resilience can be improved by employing tools to evaluate the benefits of disaster mitigation measures and investment, thus reducing risk.

Based on the findings, redeveloping Xiaolin village on the original site of the village is considered feasible. In the absence of a major landslide, which caused the disaster and is not expected to reoccur, the proposed relocation site exhibits a higher debris flow risk and a similar risk of flooding and drought than that in the original site. Furthermore, when resilience was incorporated into risk assessment, the results suggested that the higher the exposure is, the higher the resilience becomes.

Resilience can effectively reduce the possibility that risk is overestimated. Disaster prevention and rescue resources are often allocated to populous areas. Therefore, highly exposed areas tend to be associated with high resilience. Resilience is a crucial indicator in the proposed framework of disaster risk assessment. Hazard, exposure, and resilience interact and should therefore be analyzed in combination.

\section{Acknowledgments}

This study was financially supported by the Research Grant NSC 101-2621-M-008-003-MY2 provided by the Ministry of Science and Technology, Taiwan.

\section{Author Contributions}

Ray-Shyan $\mathrm{Wu}$ was responsible for the overall coordination of the research team on Sustainable Management in the Chishan Basin, consisting Ching-Ho Chen and Tzu-Yi Pai. Tai-Li Lee did the literature review, collected data, and conducted analysis. Ray-Shyan $\mathrm{Wu}$ prepared the manuscript and all authors were involved in discussing the study. All authors have read and approved the manuscript.

\section{Conflicts of Interest}

The authors declare no conflicts of interest.

\section{References}

1. ISDR 2009 Global Assessment Report: Risk and Poverty in a Changing Climate. In Global Assessment Report on Disaster Risk Reduction; United Nations: Geneva, Switzerland, 2009.

2. Ku, C.Y.; Chen, C.J.; Chang, I.W.; Hsu, S.M.; Chen, N.C.; Wen, H.Y. Study on the Assessment of Regional Railfall-Induced Landslide Hazards under Extreme Climate Conditions. J. Chin. Soil Water Conserv. 2012, 43, 75-84.

3. Hashimoto, T.; Stedinger, J.R.; Loucks, D.P. Reliability, resiliency, and vulnerability criteria for water resource system performance evaluation. Water Resour. Res. 1982, 18, 14-20.

4. Huang, C.F. Discussion on Basic Methods for Risk Analysis. J. Natl. Disaster 2010, 19, 8-16.

5. Aldunce, P.; Beilin, R.; Howden, M.; Handmer, J. Resilience for disaster risk management in a changing climate: Practitioners' frames and practices. Glob. Environ. Chang. 2015, 30, 1-11.

6. Kusumastuti, R.D.; Viverita; Husodo, Z.A.; Suardi, L.; Danarsari, D.N. Developing a resilience index towards natural disasters in Indonesia. Int. J. Disaster Risk Reduct. 2014, 10, 327-340. 
7. Huang, S.M. A Study on Risk Assessment and Evacuation Strategy Planning for Debris Flow Disasters in a River Basin. Master's Thesis, National Taipei University of Education, Taipei, Taiwan, 2009.

8. Fuchs, S.; Heiss, K.; Hübl, J. Towards an empirical vulnerability function for use in debris flow risk assessment. Natl. Hazards Earth Syst. Sci. 2007, 7, 495-506.

9. Chen, B.L. Potential Analysis and Deposition Characteristics of Hillslope Debris Flows. Master's Thesis, National Pingtung University of Science and Technology, Pingtung, Taiwan, 2013.

10. Lari, S.; Crosta, G.B.; Frattini, P.; Horton, P.; Jaboyedoff, M. Regional-scale debris-flow risk assessment for an alpine valley. In Proceedings of the 5th International Conference on Debris-Flow Hazards Mitigation: Mechanics, Prediction, and Assessment, Padua, Italy, 14-17 June 2011; pp. 933-940.

11. Wang, S.Y.; Tang, G.J. Exploratory Analysis of Theoretical Basis for Integrated Natural Disaster Risk Management. J. Natl. Disaster 2009, 18, 33-38.

12. Lee, T.L. Risk Assessment of Meteorologic Disasters in Chishan Basin. Master's Thesis, National Central University, Taoyuan, Taiwan, 2014.

13. Kjeldsen, T.R.; Rosbjerg, D. Choice of reliability, resilience and vulnerability estimators for risk assessments of water resources systems. Hydrol. Sci. J. 2004, 49, 755-767.

14. Cutter, S.L.; Burton, C.G.; Emrich, C.T. Disaster resilience indicators for benchmarking baseline conditions. J. Homel. Secur. Emerg. Manag. 2010, 7, 1-51.

15. Cutter, S.L.; Barnes, L.; Berry, M.; Burton, C.; Evans, E.; Tate, E.; Webb, J. A place-based model for understanding community resilience to natural disasters. Glob. Environ. Chang. 2008, $18,598-606$.

16. Chang, P.H. A Study on the Resilience Indicators of Tansui River Basin. Master's Thesis, National Taipei University, Taipei, Taiwan, 2009.

17. Klein, R.J.; Nicholls, R.J.; Thomalla, F. Resilience to natural hazards: How useful is this concept? Glob. Environ. Chang. Part B Environ. Hazards 2003, 5, 35-45.

18. Van Aalst, M.K.; Cannon, T.; Burton, I. Community level adaptation to climate change: The potential role of participatory community risk assessment. Glob. Environ. Chang. 2008, 18, $165-179$.

19. Van Notten, P.W.; Rotmans, J.; van Asselt, M.; Rothman, D.S. An updated scenario typology. Futures 2003, 35, 423-443.

20. Yang, C.Y. Assessment of the Resilience for Flood Hazard: A Case Study of Taichung City, Longjing Township and Tungshin Township in Taichung Country. Master's Thesis, National Taipei University, Taipei, Taiwan, 2009.

21. Shaw, R.A.J.I.B. IEDM Team Climate disaster resilience: Focus on coastal urban cities in Asia. Asian J. Environ. Disaster Manag. 2009, 1, 101-116.

22. Stockholm Resilience Centre. Available online: http://www.stockholmresilience.org/research/ whatisresilience.4.aeea46911a3127427980004249.html (accessed on 2 February 2014).

23. Chen, C.J.; Wu, J.Y. The Establishment of the Evaluation System for Disaster Risk under Climate Change. J. Archit. 2011, 75, 43-60.

24. Chen, Y.M.; Hsu, C.L.; Fan, K.S. Compound Disaster Risk Analysis Framework in Taiwan. J. Crisis Manag. 2009, 6, 1-12. 
25. Huang, H.C. Disaster Reduction and Risk Managemen. J. Archit. Plan. 2009, 10, 241-244.

26. Mercer, J. Disaster risk reduction or climate change adaptation: Are we reinventing the wheel? J. Int. Dev. 2010, 22, 247-264.

27. Norris, F.H.; Stevens, S.P.; Pfefferbaum, B.; Wyche, K.F.; Pfefferbaum, R.L. Community resilience as a metaphor, theory, set of capacities, and strategy for disaster readiness. Am. J. Community Psychol. 2008, 41, 127-150.

28. Smith, K. Environmental Hazards: Assessing Risk and Reducing Disaster, 6th ed.; Taylor \& Francis: Florence, KY, USA, 2013; pp. 71-91.

(C) 2015 by the authors; licensee MDPI, Basel, Switzerland. This article is an open access article distributed under the terms and conditions of the Creative Commons Attribution license (http://creativecommons.org/licenses/by/4.0/). 